This PDF is a selection from an out-of-print volume from the National Bureau of Economic Research

Volume Title: Household Production and Consumption

Volume Author/Editor: Nestor E. Terleckyj

Volume Publisher: NBER

Volume ISBN: 0-870-14515-0

Volume URL: http://www.nber.org/books/terl76-1

Publication Date: 1976

Chapter Title: The Correlation between Health and Schooling

Chapter Author: Michael Grossman

Chapter URL: http://www.nber.org/chapters/c3962

Chapter pages in book: (p. 147 - 224) 


\title{
The Correlation between Health and Schooling*
}

\author{
MICHAEL GROSSMAN \\ GRADUATE CENTER OF THE CITY UNIVERSITY OF NEW YORK \\ AND NATIONAL BUREAU OF ECONOMIC RESEARCH
}

THE relationship between health status and socioeconomic conditions is a subject of increasing concern for both medicine and social science. Several recent studies in the United States indicate that among socioeconomic variables, years of formal schooling completed is probably the most important correlate of good health (Stockwell 1963; Fuchs 1965; Hinkle et al. 1968; Kitagawa and Hauser 1968; Auster, Leveson, and Sarachek 1969; Breslow and Klein 1971; Grossman 1972b; Silver 1972). This finding emerges whether health levels are measured by mortality rates, morbidity rates, or self-evaluation of health status, and whether the units of observation are individuals or groups. The relationship is usually statistically significant at levels of confidence of .05 or better in both simple and partial correlations.

This paper has two purposes. The first is to develop a methodological framework that can be used to introduce and discuss alternative explanations of the correlation between health and schooling. The second is to test these explanations empirically in order to select the most relevant ones and to obtain quantitative estimates of different effects. The empirical work is limited to one unique body of data and uses two measures of health that are far from ideal. The methodological framework can, however, serve as a point of departure for future research when longitudinal samples with more refined measures of current and past health and background characteristics become available.

In a broad sense, the observed positive correlation between health

* Research for this paper was supported by PHS Grant Number 5 P01 HS 00451 from the Bureau of Health Services Research and Evaluation. I owe a special debt to Victor R. Fuchs for urging me to investigate the relationship between health and schooling in detail and for interacting with me many times while I was working on the paper. I should also like to thank Gary S. Becker; Barry R. Chiswick, Reuben Gronau, F. Thomas Juster, William M. Landes, Robert T. Michael, Jacob Mincer, Melvin W. Reder, James P. Smith, Finis Welch, and Robert J. Willis for helpful comments and suggestions; and Carol Breckner, Janice Platt, and Elizabeth H. Rand for research assistance. 
and schooling may be explained in one of three ways. The first argues that there is a causal relationship that runs from increases in schooling to increases in health. The second holds that the direction of causality runs from better health to more schooling. The third argues that no causal relationship is implied by the correlation. Instead, differences in one or more "third variables," such as physical and mental ability and parental characteristics, affect both health and schooling in the same direction.

It should be noted that these three explanations are not mutually exclusive and can be used to rationalize any observed correlation between two variables. But from both a public policy and a theoretical point of view, it is important to distinguish among them and to obtain quantitative estimates of their relative magnitudes. A stated goal of public. policy in the United States is to improve the level of health of the population or of certain groups in the population. Given this goal and given the high correlation between health and schooling, it might appear that one method of implementing it would be to increase government outlays on schooling. In fact, Auster, Leveson, and Sarachek (1969) suggest that the rate of return on increases in health via higher schooling outlays far exceeds the rate of return on increases in health via higher medical care outlays. This argument assumes that the correlation between health and schooling reflects only the effect of schooling on health. If, however, the causality ran the other way or if the third-variable hypothesis were relevant, then increased outlays on schooling would not accomplish the goal of improved health.

From a theoretical point of view, recent new approaches to demand theory assume that consumers produce all their basic objects of choice, called commodities, with inputs of market goods and services and their own time (Becker 1965; Lancaster 1966; Muth 1966; Michael 1972; Ghez and Becker 1973; Michael and Becker 1973). Within the context of the household production function model, there are compelling reasons for treating health and schooling as jointly determined variables. It is reasonable to assume that healthier students are more efficient producers of additions to the stock of knowledge, or human capital, via formal schooling. If so, then they would tend to increase the quantity of investment in knowledge they demand as well as the number of years they attend school. Similarly, the efficiency with which individuals transform medical care and other inputs into better health might rise with schooling. This would tend to create a positive correlation between schooling and the quantity of health demanded. Moreover, genetic and early childhood environmental factors might be im- 
portant determinants of both health and intelligence. ${ }^{1}$ Since intelligence and parental characteristics are key variables in the demand curve for schooling, the estimated effect 'of schooling on health would, under certain conditions, be biased if relevant third variables were omitted from the demand curve for health. ${ }^{2}$

The plan of this paper is as follows. In Section I, I formulate a recursive system whose two fundamental equations are demand curves for health and schooling. The former equation is based on a model of the demand for health that $\mathrm{I}$ have developed in previous work (Grossman 1972a, 1972b). The system as a whole is similar to those that have been used by Bowles (1972); Griliches and Mason (1972); Lillard (1973); and Leibowitz (1974) to study relationships among schooling, ability, and earnings. In Section II, I describe the empirical implementation of the model to data contained in the NBER-Thorndike sample, and in Section III, I present empirical estimates. In Section IV, I expand the model by treating current health and current market wage rates as simultaneously determined variables and show the results of estimating wage and health functions by two-stage least squares. Finally, in Section V, I examine the mortality experience of the NBER-Thorndike sample between 1955 and 1969.

\section{THE MODEL}

\section{A. Demand Curve for Health}

Elsewhere (Grossman 1972a, 1972b), I have constructed and estimated a model of the demand for health. For the purpose of this paper, it will be useful to summarize this model and to comment on the nature of the reduced-form demand curve for health capital that it generates. As a point of departure, I assume that individuals inherit an initial stock of health which depreciates with age, and which can be increased by investment. By definition, net investment in the stock of health equals gross investment minus depreciation:

$$
H_{t+1}-H_{t}=I_{t}-\delta_{t} H_{t}
$$

where $H_{t}$ is the stock of health at age $t, I_{t}$ is gross investment, and $\delta_{t}$ is the rate of depreciation. Direct inputs into the production of gross

\footnotetext{
${ }^{1}$ Early childhood environment is shaped, to a large extent, by parental characteristics such as schooling, family income, and socioeconomic status.

${ }^{2}$ The effect of schooling on the health of adults would not be biased by the omission of third variables if one had a perfect measure of their health during the years that they attended school, and if schooling were the only determinant of the efficiency of nonmarket production. For a complete discussion of this point, see Section I, part B.
} 
investments in health include the time expenditure of the consumer, medical care, proper diet, housing facilities, and other market goods and services as well.

In the model, consumers demand health for two reasons. As a consumption commodity, it directly enters their utility functions, or put differently, illness is a source of disutility. As an investment commodity, it determines the total amount of time available for work in the market sector of the economy, where consumers produce money earnings, and for work in the nonmarket or household sector, where they produce commodities that enter their utility functions. The investment motive for demanding health is present because an increase in the stock of health lowers the amount of time lost from market and nonmarket activities in any given period, say a year, due to illness and injury. The monetary value of this reduction in lost time measures the return to an investment in health.

In much of my work, I have ignored the consumption aspects of the demand for health and have developed in detail a pure investment version of the general model. ${ }^{3}$ The pure investment model generates powerful predictions from simple analysis and innocuous assumptions and also emphasizes the difference between health capital and other forms of human capital. In particular, persons demand knowledge capital because it influences their market and nonmarket productivity. On the other hand, they demand health capital because it produces an output of healthy time that can then be allocated to the production of money earnings and commodities. Since the output of health capital has a finite upper limit of 8,760 hours in a year ( 365 days times 24 hours per day), the marginal product of this capital diminishes. This suggests a healthy-time production function of the form

$$
h_{t}=8,760-B_{t}{ }^{-C}
$$

where $h_{t}$ is healthy time and $B$ and $C$ are positive constants. From (2), the marginal product of health capital would be

$$
G_{t}=\left(\partial h_{t} / \partial H_{t}\right)=B C H_{t}^{-C-1}
$$

In the pure investment model, given constant marginal cost of gross investment in health, the equilibrium stock of health at any age can be determined by equating the marginal monetary rate of return on health capital to the opportunity cost of this capital. If $W_{t}$ is the hourly wage rate, and if $\pi_{t}$ is the marginal cost of gross investment in health,

\footnotetext{
- ${ }^{3}$ In the pure investment model, the marginal utility of healthy time or the marginal disutility of sick time equals zero.
} 
then the rate of return or the marginal efficiency of health capital can be defined as

$$
\gamma_{t}=W_{t} G_{t} / \pi_{t}
$$

In equilibrium,

$$
\gamma_{t}=r-\tilde{\pi}_{t}+\delta_{t}
$$

where $r$ is the rate of interest and $\tilde{\pi}_{t}$ is the continuously compounded percentage rate of change in marginal cost with age. ${ }^{4}$ Equations 3, 4, and 5 imply a demand curve for health capital or a marginal efficiency of capital schedule of the form ${ }^{5}$

$$
\ln H_{t}=\ln B C+\epsilon \ln W_{t}-\epsilon \ln \pi_{t}-\epsilon \ln \delta_{t}
$$

where $\epsilon=1 /(1+C)$ is the elasticity of the schedule.

By making assumptions about the nature of the depreciation rate function and the marginal cost of gross investment function, I have used equation 6 to obtain and estimate a reduced-form demand curve for health capital. If $\tilde{\delta}$ is the constant continuously compounded rate of increase in the rate of depreciation with age, and if $\delta_{1}$ is the rate of depreciation during some initial period, then

$$
\ln \delta_{t}=\delta_{1}+\tilde{\delta} t
$$

It should be noted that $\delta_{1}$ is not the rate of depreciation at the very beginning of the life cycle. Instead, it is the rate at an age, say age sixteen, when individuals rather than their parents begin to make their own decisions.

I develop an equation for marginal cost by letting the gross investment production function be a member of the Cobb-Douglas class:

$$
\ln I_{t}=\alpha \ln M_{t}+(1-\alpha) \ln T_{t}+\rho E
$$

The new variables in this equation are $M_{t}$, a market good or a vector of market goods used to produce gross investments in health; $T_{\ell}$, an

${ }^{4}$ Equilibrium condition 5 assumes that gross investment in health is always positive. For a discussion of this point, see Grossman (1972a, pp. 233-234).

${ }^{5}$ From equation 3

$$
\ln G_{t}=\ln B C-(C+1) \ln H_{t}
$$

Substitute $\ln \gamma_{t}-\ln W_{t}+\ln \pi_{t}$ for $\ln G_{t}$ in this equation, and solve for $\ln H_{t}$ to obtain

$$
\ln H_{t}=\ln B C+\epsilon \ln W_{t}-\epsilon \ln \pi_{t}-\epsilon \ln \gamma_{t}
$$

where $\epsilon=1 /(1+C)$. Replacing $\gamma_{t}$ by $r-\bar{\pi}_{t}+\delta_{t}$ in the last equation and assuming that the real own rate of interest, $r-\tilde{\pi}_{l}$, is equal to zero, one obtains equation 6 . For a justification of the assumption that $r-\tilde{\pi}_{l}$ is zero, see Grossman (1972b, p. 42). 
input of the consumer's own time; and $E$, an index of the stock of knowledge, or human capital. ${ }^{6}$ The new parameters are $\alpha$, the output elasticity of $M_{t}$ or the share of $M_{t}$ in the total cost of gross investment; $(1-\alpha)$, the output elasticity of $T_{t}$; and $\rho$, the percentage improvement in nonmarket productivity due to human capital. It is natural to view medical care as an important component of $M_{t}$, although studies by Auster, Leveson, and Sarachek (1969); Grossman (1972b); and Benham (in progress) reach the tentative conclusion that medical care has, at best, a minor marginal impact on health. ${ }^{7}$

Equations 6,7 , and 8 generate a reduced-form demand curve for health capital given by ${ }^{8}$

$$
\ln H_{t}=\alpha \epsilon \ln W_{t}-\alpha \epsilon \ln P_{t}+\rho \epsilon E-\tilde{\delta} \epsilon t-\epsilon \ln \delta_{1}
$$

where $P_{t}$ is the price of $M_{t}$. It should be realized that although the subscript $t$ refers to age, $H_{t}$ will vary among individuals as well as over the life cycle of a given individual. It should also be realized that the functional form of equation 9 is one that is implied by the model rather than one that is imposed on data for "convenience." According to the equation, the quantity of health capital demanded should be positively related to the hourly wage rate and the stock of human capital and should be negatively related to the price of $M_{t}$, age, and the rate of depreciation in the initial period.

In previous empirical work (Grossman 1972b, Chapter V), I fitted equation 9 to data for individuals who had finished their formal schooling. I measured health by self-rated health status, and alternatively by sick time, and measured the stock of knowledge, or human capital, by years of schooling completed. Since I had no data on depreciation rates of persons of the same age, I assumed that $\ln \delta_{1}$ was not correlated with the other variables on the right-hand side of equation 9. Put differently, I treated $\ln \delta_{1}$ as the random disturbance term in the reducedform demand curve.

\footnotetext{
${ }^{6}$ Note that certain inputs in the $M$ vector, such as cigarette smoking and alcohol consumption, have negative marginal products in the gross investment function. They are purchased because they also produce other commodities, such as "smoking pleasure." Therefore, joint production occurs in the household. For an analysis of this phenomenon, see Grossman (1971). Note also that, if health were produced in a family context, then $T_{t}$ might be a vector of time inputs of various family members.

${ }^{7}$ Grossman and Benham (1974) produce some evidence to the contrary, but this evidence should also be viewed as tentative.

${ }^{8}$ For a derivation of equation 9, see Grossman (1972b, Appendix D). This equation, as well as the remainder of those in this paper, does not contain an intercept, because all variables are expressed as deviations from their respective means.
} 
In general, my empirical results were consistent with the predictions of the model. In particular, with age, the wage rate, and several other variables held constant, schooling had a positive and significant effect on health. ${ }^{9}$ I interpreted this result as evidence in support of the hypothesis that schooling raises the efficiency with which health is produced. That is, I interpreted it in terms of a causal relationship that runs from more schooling to better health. If, however, the unobserved rate of depreciation on health capital in the initial period were correlated with schooling, or if schooling were an imperfect measure of the stock of human capital, then my finding would be subject to more than one interpretation.

\section{B. A General Recursive System}

I now show that a general model of life-cycle decision making would lead to a negative relationship between schooling and the rate of depreciation. Moreover, this model would predict positive relationships between schooling and other components of nonmarket efficiency; and between schooling and additional third variables that should, under certain conditions, enter equation 9. These relationships arise because, in the context of a life-cycle model, the amount of schooling persons acquire and their health during the time that they attend school are endogenous variables. I do not develop the model in detail but instead rely heavily on previous work dealing with the demand for preschool and school investments in human capital, and the demand for child quality. ${ }^{10}$

1. Demand Curve for Schooling. The optimal quantity of school investment in human capital in a given year and the number of years of formal schooling completed should be positive functions of the efficiency with which persons transform teachers' services, books, their own time, and other inputs into gross additions to the stock of knowledge. As Lillard (1973, p. 32) points out, efficiency in producing human capital via schooling is determined by factors such as physical

\footnotetext{
${ }^{9}$ This finding complements the negative relationships among schooling and various age-adjusted mortality rates that are reported in a number of studies. See Stockwell (1963); Fuchs (1965); Hinkle et al, (1968); Kitagawa and Hauser (1968); Auster, Leveson, and Sarachek (1969); Breslow and Klein (1971); and Silver (1972).

${ }^{10}$ For models of the determination of optimal investment in human capital, see, for example, Becker (1967); Ben-Porath (1967); and Lillard (1973). For models of the demand for child quality, see, for example, Leibowitz (1972); Ben-Porath (1973); DeTray (1973); and especially Willis (1973). For studies that view preschool investment in human capital as one aspect of child quality, see, for example, Lillard (1973) and Leibowitz (1974).
} 
ability, mental ability (intelligence), and health. ${ }^{11}$ Another reason for expecting a positive effect of health on schooling is that the returns from an investment in schooling last for many periods. Since health status is positively correlated with life expectancy, it should be positively correlated with the number of periods over which returns can be collected. In addition to efficiency and to the number of periods over which returns accrue, the opportunity to finance investments in. human capital, measured by parents' income or by parents' schooling, should be a key determinant of the quantity of schooling demanded.

Let the factors that determine variations in years of formal schooling completed $(S)$ among individuals be summarized by a demand curve of the form

$$
S=a_{1} \ln H_{1}+a_{2} X
$$

where $X$ is a vector of all other variables besides health that influences $S$. In a manner analogous to the interpretation of $\delta_{1}, H_{1}$ may be interpreted as health capital at the age (age sixteen) when individuals begin to make their own decisions. I will assume, however, that a given person's health capital at age sixteen is highly correlated with his or her own health capital at the age (age five or six) when formal schooling begins. One justification for this assumption is that the rate of increase in the rate of depreciation might be extremely small and even zero at young ages. ${ }^{12}$

The demand curve for schooling given by equation 10 differs in a fundamental respect from the demand curve for health given by equation 9. Since the production function of gross investment in health exhibits constant returns to scale and since input prices are given, the marginal cost of gross investment in health is independent of the quantity of investment produced. Therefore, consumers reach their desired stock of health capital immediately, and equation 9 represents a

${ }^{11}$ A common specification of the production function of new human capital at age $t$, due originally to Ben-Porath (1967), is

$$
\ln Q_{t}=\ln B+\alpha_{1} \ln s_{t} E_{t}+\alpha_{2} \ln D_{t}
$$

where $s_{t}$ is the proportion of the existing stock of human capital allocated to the production of more human capital, $D_{t}$ is an input of market goods and services, and $\alpha_{1}+$ $\alpha_{2}<1$. Following Lillard (1973), I assume that ability and health primarily affect the Hicks-neutral technology parameter $B$, rather than the stock of human capital that individuals possess when they first begin to make their own decisions. Leibowitz (1974) stresses the effect of ability on the preschool stock of human capital but reaches the same conclusion with regard to the effect of ability on schooling.

${ }^{12}$ Indeed, at young ages, the rate of depreciation might fall rather than rise with age. 
demand curve for an equilibrium stock of capital at age $t$. Implicit in this equation is the assumption that people never stop investing in their health. ${ }^{13}$

On the other hand, following Becker (1967) and Ben-Porath (1967), I allow the marginal cost of gross investment in knowledge to be a positive function of the rate of production of new knowledge. ${ }^{14}$ Thus, consumers do not reach their equilibrium stock of knowledge immediately, and equation 10 represents a demand curve for the equilibrium length of the investment period, measured by the number of years of formal schooling completed. Since persons typically have left school by age thirty, investment in knowledge ceases after some point in the life cycle. ${ }^{15}$

2. Demand Curve for Children's Health. Although the health and intelligence of children depend partly on genetic inheritance, these variables are not completely exogenous in a life-cycle model. In particular, they also depend on early childhood environmental factors, which are shaped to a large extent by parents. ${ }^{16}$ If children's health is viewed as one aspect of their quality, then one can conceive of a demand curve for $H_{1}$ whose key arguments are variables that determine the demand for child quality. Children's health should rise with their parents' income if quality has a positive income elasticity and should rise with their parents' schooling if persons with higher schooling levels are relatively more efficient producers of quality children than of other commodities. Most important for my purposes, the quantity of $H_{1}$ demanded should be negatively related to $\delta_{1}$. This follows because, regardless of whether one is examining the demand for children's health capital or adults' health capital, an increase in the rate of depreciation raises the price of such capital.

${ }^{13}$ One justification for this assumption is that it is observed empirically that most individuals make positive outlays on medical care throughout their life cycles.

${ }^{14}$ This assumption is required because, from the point of view of any one person, the marginal product of the stock of knowledge is independent of the stock. For a complete discussion of this point, see Becker (1967) and Ben-Porath (1967). Grossman (1972a, pp. 234-235) compares and contrasts in detail the alternative assumptions made about the marginal products of health and knowledge capital and about the marginal costs of producing gross additions to these two stocks.

${ }^{15}$ After leaving school, persons can continue to acquire human capital via investments in on-the-job training. I assume that human capital obtained in this manner is a much less relevant determinant of efficiency in the production of health than human capital obtained via formal schooling. For analyses of the forces that cause the quantity of investment in human capital to decline with age, see Becker (1967); Ben-Porath (1967); and Mincer (1970, 1972).

${ }^{16}$ This point is emphasized by Lillard (1973) and especially by Leibowitz (1974). 
Let the demand curve for children's health be given by

$$
\ln H_{1}=b_{1} Y-\epsilon^{\prime} \ln \delta_{1}
$$

In equation $11, Y$ is a vector of all other variables in addition to $\delta_{1}$ that affects $H_{1}$, and $\epsilon^{\prime}$ is the price elasticity of $H_{1}{ }^{17}$ This elasticity will not, in general, equal the price elasticity of $H_{t}(\epsilon)$. Surely, in a developed economy such as the United States, a healthy child is primarily a consumption commodity. Since my model treats adult health as primarily an investment commodity, the substitution effect associated with a change in the price of $H_{t}$ will differ in nature from the substitution effect associated with a change in the price of $H_{1}$.

It should be realized that the stock of health capital inherited at birth does not enter equation 11 directly. Given constant marginal cost of gross investment in health, any discrepancy between the inherited stock of children's health and the stock that their parents demand in the period immediately following birth would be eliminated instantaneously. This does not mean that $H_{1}$ is independent of genetic inheritance and birth defects. Variations in these factors explain part of the variation in $\delta_{1}$ among children of the same age. According to this interpretation, children with inferior genetic characteristics or birth defects would have above-average rates of depreciation, and their parents would demand a smaller optimal quantity of $H_{1}{ }^{18}$ Of course, one could introduce a direct relationship between current and lagged stock by dropping the assumption of constant marginal cost. Such a framework would, however, greatly complicate the interpretation and empirical estimation of demand curves for children's health and adults' health. Consequently, I will not pursue it in this paper.

3. Human Capital Equation. To complete the analytical framework, it is necessary to specify an equation for the stock of knowledge, or human capital, after the completion of formal schooling. Recall that it is this stock that determines the efficiency with which adult health is produced. Assume that the stock $(E)$ depends on years of formal schooling completed $(S)$ and a vector of other variables $(Z)$ as in ${ }^{19}$

\footnotetext{
${ }^{17}$ Along similar lines, one could specify a demand curve for children's intelligence. For one specification and some empirical estimates, see Leibowitz (1974).

${ }^{18}$ The same conclusion would be reached if an inferior genetic endowment or a birth defect lowered the amount of gross investment in health obtained from given amounts of medical care and other inputs.

${ }^{19}$ The variable $E$ does not have an age subscript, because it is the stock of knowledge after schooling ends. If the rate of depreciation on knowledge capital were positive, $E$ would fall with age. I assume that this effect is small enough to be ignored, at least at most stages of the life cycle.
} 


$$
E=c_{1} S+c_{2} Z
$$

The variables in $Z$ include the initial or inherited stock of human capital and determinants of the "average" quantity of new knowledge produced per year of school attendance, such as ability, health, quality of schooling, and parental characteristics. In one important respect, equation 12 is misspecified, for the function that relates $E$ to $S$ and $Z$ is almost certainly nonlinear. ${ }^{20}$ In this paper, $I$ use equation 12 as a first approximation in assessing the biases that arise when determinants of human capital other than schooling are omitted from the demand curve for health. In future work, I plan to modify the assumption of linearity.

4. Comments and Interpretation of Health-Schooling Relationships. The system of equations that I have just developed provides a coherent framework for analyzing and interpreting health-schooling relationships and for obtaining unbiased estimates of the "pure" effect of schooling on health. Before I turn to these matters, it will be useful to make a few comments about the general nature of this system. The stock of knowledge is a theoretical concept and is difficult to quantify empirically. Because it will not, in general, be possible to estimate the human capital function given by 12 , substitute it into the demand curve for adults' health given by 9 . This reduces the system to three basic equations, which are demand curves for children's health, schooling, and adults' health: ${ }^{21}$

$$
\begin{gathered}
\ln H_{1}=b_{1} Y-\epsilon^{\prime} \ln \delta_{1} \\
S=a_{1} \ln H_{1}+a_{2} X
\end{gathered}
$$

and

$$
\ln H_{t}=\alpha \epsilon \ln W-\alpha \epsilon \ln P+c_{1} \rho \epsilon S+c_{2} \rho \epsilon Z-\tilde{\delta} \epsilon t-\epsilon \ln \delta_{1}
$$

Since the endogenous variables are determined at various stages in the life cycle, these three equations constitute a recursive system rather than a full simultaneous-equations model. For example, although children's health is the endogenous variable in equation 11 , it is predetermined when students select their optimal quantity of schooling at age sixteen. Similarly, schooling is predetermined when adults select

\footnotetext{
${ }^{20}$ Employing Ben-Porath's model of investment in human capital, Lillard (1973) obtains a specific solution for the stock of human capital as a function of schooling, ability, and age. His equation is highly nonlinear.

${ }^{21}$ From now on, age subscripts are deleted from all variables on the right-hand side of the demand curve for adults' health except the rate of depreciation in the initial period.
} 
their optimal quantity of health capital at age $t$. It is well known that estimation of each equation in a recursive system by ordinary least squares is equivalent to estimation of the entire system by the method of full-information maximum likelihood. ${ }^{22}$

I have specified demand curves for adults' health and for children's health, but I have not specified a demand curve for health at an age when persons are still in school but are making their own decisions. Formally, if the decision-making process begins at age sixteen, and if schooling ends at age $t^{*}$, then I ignore demand at age $j$, where 16 $<j \leqslant t^{*}$. It might appear that I have done this to avoid a problem of instability in the system. Specifically, variations in $H_{1}$ would cause the quantity of human capital produced in period $1\left(Q_{1}\right)$ to vary. An increase in $Q_{1}$ would raise the stock of human capital $\left(E_{2}\right)$ in period 2, which should raise efficiency in the production of health and the quantity of $\mathrm{H}_{2}$ demanded. In turn, the increase in $\mathrm{H}_{2}$ would raise $Q_{2}$, and so on. Although this process is potentially unstable, it is observed empirically that persons do not attend school throughout their life cycles. Rather, the equilibrium quantities of $S$ and the stock of human capital $\left(E=E_{t}^{*}\right)$ are reached at fairly young ages, and the system would retain its recursive nature even if a demand curve for $H_{j}$ were introduced.

The simultaneous determination of health and knowledge in the age. interval $16 \leqslant j<t^{*}$ does suggest that $E_{t}^{*}$ should depend either on all quantities of $H$, or on an average quantity of $H$, in this interval. But such an average undoubtedly is highly correlated with the stock of health at age sixteen. This simultaneous determination also blurs to some extent the sharp distinction that I have drawn between knowledge capital as a determinant of productivity and health capital as a determinant of total time. Note, however, that $E_{t}^{*}$ depends on $H_{1}$ rather than on the contemporaneous stock of health. Therefore, the distinction between health and knowledge capital remains valid as long as it is applied to contemporaneous stocks of the two types of capital at ages greater than $t^{*}$.

The wage rate and the stock of human capital obviously are positively correlated, yet I treat the wage rate as an exogenous variable in the recursive system. The wage rate enters the demand curve for adults' health in order to assess the pure effect of schooling on nonmarket productivity, with market productivity held constant. The wage

\footnotetext{
${ }^{22}$ See, for example, Johnston (1963). This proposition is valid only if the unspecified disturbance terms in the equations are mutually independent.
} 
should have an independent and positive impact on the quantity of health demanded, because it raises the monetary value of a reduction in sick time by a greater percentage than it raises the cost of producing such a reduction. If market and nonmarket productivity were highly correlated, it would be difficult to isolate the pure nonmarket productivity effect, but this is an empirical issue that can ultimately be decided by the data. As long as the current stock of health is not a determinant of the current stock of human capital, nothing would be gained by specifying an equation for the wage rate. Until Section IV, I assume that, at ages greater than $t^{*}, E_{t}$ and, therefore, $W_{t}$ do not depend on $H_{t}$.

In the remainder of this section, I discuss the interpretation and estimation of health-schooling relationships within the context of the recursive system. Given an appropriate measure of the rate of depreciation in the initial period, an ordinary least squares fit of equation $9^{\prime}$ would yield an unbiased estimate of the pure effect of schooling on health. Now suppose that no measure of $\delta_{1}$ is available. From equation $11, H_{1}$ is negatively related to $\delta_{1}$, and from equation $10, S$ is positively related to $H_{1}$. Therefore, $S$ is negatively related to $\delta_{1}$. Since an increase in $\delta_{1}$ causes $H_{t}$ to fall, the expected value of the regression coefficient of $S$ in equation $9^{\prime}$ would be an upward-biased estimate of the relevant population parameter. This is the essence of the reverse causality interpretation of an observed positive relationship between schooling and health. Due to the prediction of the recursive system that healthier students should attend school for longer periods of time, the effect of schooling on health would be overstated if $\delta_{1}$ were not held constant in computing equation $9^{\prime}$.

In general, it should be easier to measure the stock of health in the initial period empirically than to measure the rate of depreciation in this period. Therefore, the easiest way to obtain unbiased estimates of the parameters of equation $9^{\prime}$ would be to solve equation 11 for $\ln$ $\delta_{1}$ and substitute the resulting expression into $9^{\prime}$ :

$\ln H_{t}=\alpha \epsilon \ln W-\alpha \epsilon \ln P+c_{1} \rho \epsilon S+c_{2} \rho \epsilon Z-\tilde{\delta} \epsilon t$

$$
+\left(\epsilon / \epsilon^{\prime}\right) \ln H_{1}-\left(b_{1} \epsilon / \epsilon^{\prime}\right) Y
$$

A second justification for this substitution is that $H_{1}$ is one of the variables in the $Z$ vector, because it is a determinant of the average quantity of new knowledge produced per year of school attendance. Consequently, In $H_{1}$ should enter the regression whether or not In 
$\delta_{1}$ can be measured, and the elimination of $\ln \delta_{1}$ from $9^{\prime}$ makes it simpler to interpret variations in key variables within the recursive system. ${ }^{23}$

Formally, if $Z=Z^{\prime}+c_{3} \ln H_{1}^{\prime}$, then the regression coefficient of ln $H_{1}$ in equation $9^{\prime \prime}$ would be $c_{3} c_{2} \rho \epsilon+\left(\epsilon / \epsilon^{\prime}\right)$. Although it would not be possible to isolate the two components of this coefficient, both should be positive. Therefore, one can make the firm prediction that $H_{1}$ should have a positive effect on $H_{t}$. This relationship arises not because of any direct relationship between current and lagged stock but because $H_{1}$ is negatively correlated with the depreciation rate in the initial period and is positively correlated with the equilibrium stock of human capital.

The "third variable" explanation of the observed positive correlation between health and schooling asserts that no causal relationship is implied by this correlation. Instead, differences in one or more third variables cause health and schooling to vary in the same direction. The most logical way to introduce this hypothesis and to examine its relevance within the context of the recursive system is to associate third variables with the $Y$ vector in the demand curve for children's health and with the $X$ vector in the demand curve for schooling. Many of the variables in these two vectors represent factors, such as parents' schooling and parents' income, that shape early childhood environment. If years of formal schooling completed were the only determinant of the stock of human capital, and if one had a perfect measure of $\delta_{1}$ or $H_{1}$, then the third-variable effect would operate solely via the relationship between $H_{1}$ and $H_{t}$. That is, provided $H_{1}$ were held constant, the estimated schooling parameter in equation $9^{\prime \prime}$ would not be biased by the omission of environmental variables that induce similar changes in schooling and children's health. ${ }^{24}$

The situation would be somewhat different if one had no measure of $\delta_{1}$ or $H_{1}$. Then a variable in the $Y$ vector might have a positive effect on $H_{t}$ if it were negatively correlated with $\delta_{1}{ }^{25}$ The assumption of a

\footnotetext{
${ }^{23}$ If $\ln H_{1}$ varied with $S$ and $\ln \delta_{1}$ held constant, then one would be imposing a negative correlation between $Y$ and $X$. Since the variables in these two vectors primarily reflect childhood environment, such a correlation is not plausible.

${ }^{24}$ Indeed, according to equation 9", an increase in $Y$, with in $H_{1}$ constant, would cause $\ln H$, to fall. Note, however, that, if $\ln \delta_{1}$ and $Y$ were independent, then $Y$ should be omitted from $\left(9^{\prime \prime}\right)$.

${ }^{25}$ If equation $9^{\prime \prime}$ were fitted with $\ln H_{1}$ omitted, the expected value of the regression coefficient of $Y$ would be $\left(\epsilon / \epsilon^{\prime}\right)\left(\hat{b}-b_{1}\right)$, where $\hat{b}$ is the partial regression coefficient of In $H_{1}$ on $Y$, with other variables in the demand curve for adults' health held constant. If $\hat{b}$ were positive, the expected value of the regression coefficient of $\ln H_{t}$ on $Y$ would be positive provided $\hat{b}>b_{1}$.
} 


\section{The Correlation between Health and Schooling 161}

negative correlation between $Y$ and $\delta_{1}$ is not as arbitrary as it may seem, for $\delta_{1}$ is not entirely an exogenous variable. To the extent that variations in $\delta_{1}$ reflect variations in birth defects, these defects should depend in part on the quantity and quality of prenatal care, which in turn may be related to the characteristics of parents. For instance, at an empirical level, birth weight is positively correlated with mothers' schooling. ${ }^{26}$ Moreover, there is evidence that physical health is influenced by mental well-being. ${ }^{27}$ Some of the differences in $\delta_{1}$ among individuals may be associated with differences in mental well-being that are created by early-childhood environmental factors.

In an intermediate situation, one may have some data on past health, but it may be subject to errors of observation. Then it would make sense to include $Y$ in a regression estimate of equation $9^{\prime \prime}$ in order to improve the precision with which past health is estimated. In general, $Y$ would have a larger effect on current health, the greater is the error variance in $H_{1}$ relative to the total variance.

If efficiency in the production of adults' health were not determined solely by years of formal schooling completed, then third variables could have effects on current health independent of their effects on past health. These effects are represented by the coefficients of the variables in the $Z$ vector in equation $9^{\prime \prime}$. Since some of these variables also enter the $X$ vector in the demand curve for schooling, the estimated impact of schooling on current health would be biased if the $Z$ variables were excluded from the demand curve for adults' health. I have interpreted the variables in this vector primarily as measures of a person's capacity to assimilate new knowledge in a given year of school attendance and have associated them with physical and mental ability, health, parental characteristics, and school quality. In general, it will not be possible to distinguish the effects of $Y$ variables from those of $Z$ variables in the demand curve for health. For example, given an imperfect measure of past health, parents' schooling may have a positive impact on current health because it is positively correlated with past health or because it is one determinant of the stock of human capital.

The overlap between elements in the $Z$ vector and those in the $X$ and $Y$ vectors suggests that certain third variables must operate in an indirect manner only in the demand curve for adults' health. Clearly, it would not be feasible to vary schooling, with past health and all of

\footnotetext{
${ }^{26}$ See, for example, Masland (1968).

${ }^{27}$ See, for example, Palmore (1969a, 1969b).
} 
the other variables in the $X$ vector held constant. That is, one could not use schooling and all of its systematic determinants as independent variables in a regression with current health as the dependent variable. Specifically, intelligence, like children's health, is one aspect of the quality of children that depends on genetic inheritance and early childhood environment. Therefore, these factors may affect the current stock of health solely through their influence on intelligence. ${ }^{28}$

At this point, two caveats with regard to the third variable effect are in order. First, I have assumed that efficiency in health production is a function of a homogeneous stock of knowledge, or human capital. Efficiency may, however, depend on "general" human capital (knowledge) and on "specific" (health-related) human capital. It is plausible to associate schooling and mental intelligence with general capital and to associate physical characteristics with specific capital. Suppose that genetic inheritance affects physical and mental ability and suppose that an inferior genetic endowment is not reflected in poor health until later stages of the life cycle. Then, there is a rationale for including physical ability in the demand curve for health, even if this dimension of ability is not directly related to the quantity of schooling demanded. Indeed, given the health-specific nature of physical ability, it should have a larger effect on current health than mental ability. On the other hand, given the schooling-specific nature of mental ability, it should have a larger impact on schooling than physical ability.

Second, if one considers the production of health in a family context, then years of formal schooling completed by one's spouse becomes a relevant third variable. To anticipate the empirical work in the following sections of this paper, consider the process by which the health of married men is produced. Typically, such men devote most of their time to market production, while their wives devote most of their time to nonmarket production. This suggests that wives' time should be an important input in the production of husbands' health. If an increase in wives' schooling raises their nonmarket productivity, then it would tend to raise the quantity of husbands' health demanded. To be sure, an increase in schooling should raise the value of time, measured by the potential market wage rate, as well as nonmarket productivity. ${ }^{29}$ Suppose that wives' schooling but not their potential market wage

\footnotetext{
${ }^{28}$ For a similar discussion with regard to the effects of parental characteristics and intelligence on earnings, see Leibowitz (1974).

${ }^{29}$ I do not consider here the difficult problem of measuring the value of time of persons not in the labor force. For discussions of this issue, see Gronau (1973) and Heckman (1974).
} 
The Correlation between Health and Schooling 163

were included in a demand curve for husbands' health. Then the wives' schooling parameter would be $\epsilon\left(\rho_{f}-\alpha_{f} \hat{W}_{f}\right)$, where $\rho_{f}$ is the percentage increase in wives' nonmarket productivity due to a one year increase in schooling, $\hat{W}_{f}$ is the percentage change in market productivity, and $\alpha_{f}$ is the share of wives' time in the total cost of gross investment in husbands' health. This parameter would be positive provided $\rho_{f}$ exceeded $\alpha_{f} \hat{W}_{f}$. Thus, it would definitely be positive if schooling raised market and nonmarket productivity by the same percentage. ${ }^{30}$

To summarize, given data on current health, past health, and third variables for persons who had completed formal schooling, one could estimate the demand curves for adults' health and schooling given by equations $9^{\prime \prime}$ and 10. The coefficient of schooling in equation $9^{\prime \prime}$ would indicate the contribution of this variable to current health, with past health and third variables held constant. That is, it would measure the degree to which more schooling causes better health. The coefficient of past health in equation 10 would measure the extent to which good health at young ages induces people to attend school for longer periods of time. Since the two equations constitute a recursive system rather than a full simultaneous-equations model, consistent estimates of each may be obtained by ordinary least squares.

\section{EMPIRICAL IMPLEMENTATION OF THE MODEL}

\section{A. The Sample}

I have used data contained in the NBER-Thorndike sample to estimate health and schooling functions. This is a sample drawn from a population of 75,000 white males who volunteered for, and were accepted as candidates for, Aviation Cadet status as pilots, navigators, or bombardiers in the Army Air Force in the last half of $1943 .{ }^{31}$ To be accepted as a candidate, a man had to pass a physical examination and the Aviation Cadet Qualifying Examination, which measured scholastic aptitude and achievement. According to Thorndike and Hagen, the minimum passing score on the Qualifying Examination was "one that could be achieved by about half of high-school graduates (1959, p. 53)." Thus, the candidates were selected almost entirely from the upper half of the scholastic ability (IQ) distribution of all draft-eligible white males in the United States in 1943. After passing the Qualifying Examination, candidates were given seventeen specific

\footnotetext{
${ }^{30}$ Since $\alpha_{f}<1, \rho_{f}>\alpha_{f} \hat{W}_{f}$ if $\rho_{f}=\hat{W}_{f}$.

${ }^{31}$ For complete descriptions of the sample, see Thorndike and Hagen (1959) and Taubman and Wales (1974).
} 
tests that measured five basic types of ability: general intelligence, numerical ability, visual perception, psychomotor control, and mechanical ability. ${ }^{32}$ A candidate's scores on these tests determined whether he was accepted as an Aviation Cadet for training in one of the programs, and his subsequent performance in training school determined whether he actually served in the Air Force.

In 1955, Robert L. Thorndike and Elizabeth Hagen collected information on earnings, schooling, and occupation for a civilian sample of 9,700 of these 75,000 men. In 1969, the National Bureau of Economic Research mailed a questionnaire to the members of the ThorndikeHagen sample and received 5,085 responses. In 1971, the NBER sent a supplementary questionnaire to the persons who answered its initial questionnaire and received 4,417 responses. In Section V, I examine the mortality experience of the NBER-Thorndike sample between 1955 and 1969. Until then, my empirical analysis is limited to men who responded to both NBER questionnaires, were married in 1969, were members of the labor force in that year, and did not have unknown values for certain key variables. ${ }^{33}$ The sample size of this group is 3,534 .

The NBER resurveys greatly increased the amount of information available in the data set. In particular, Thorndike and Hagen did not obtain any measures of health, parental characteristics, or spouses' characteristics. The NBER surveys included questions on all these variables and also updated the information on earnings, schooling, and work history since 1955. Most of this information was gathered in the 1969 survey. The 1971 survey collected several background characteristics that were omitted from the 1969 survey and also expanded the measures of health to include an index of past health as well as an index of current health. Since the measure of past health is available only for persons who responded to both the 1969 and 1971 surveys, I limit my analysis to such persons.

It should be emphasized that, for several reasons, the white males in the NBER-Thorndike sample by no means constitute a representative sample of all white males in the United States. First, everyone in the sample is around the same age. The mean age in 1969 was forty-seven years, and the age range was from forty-one years to fifty-five years. Second, these men are drawn mainly from the upper tails of the schooling, earnings, and scholastic ability distributions. All of them

\footnotetext{
${ }^{32}$ The identification of these five basic types of ability is due to Thorndike and Hagen (1959). It is discussed in more detail in part C of this section.

${ }^{33}$ The specific sample that $\mathbf{I}$ utilize is described in more detail in the appendix.
} 
graduated from high school, and their mean full-time salary was approximately $\$ 18,000$ in 1969 . As I have already indicated, in order to pass the Aviation Cadet Qualifying Examination in 1943, one had to have a level of scholastic ability at least as high as half of all highschool graduates. Third, since the men passed a physical examination in 1943, they were at least fairly healthy in that year. As I will show presently, their current health tends to exceed that of a random sample of white males.

It is plausible to postulate that the effect of past health on schooling and the effect of schooling on current health decline as the levels of these variables increase. Therefore, it may be more difficult to uncover significant health-schooling relationships in the NBER-Thorndike sample than in other samples. In particular, with past health held constant, any impact of schooling on current health represents the effect of college attendance versus completion of formal schooling after graduation from high school. As a corollary, if significant healthschooling relationships exist in the NBER-Thorndike sample, even more significant relationships may exist in the general population. The main advantage in using the sample to study these relationships is that data on past health and a fairly wide set of potential third variables are available.

\section{B. Measurement of Health}

The stock of health, like the stock of knowledge, is a theoretical concept that is difficult to define and quantify empirically. A proxy for it is, however, available in the 1969 NBER-Thorndike survey. The men in the sample were asked whether the state of their general health was excellent, good, fair, or poor. I use their response to this question as an index of the amount of health capital they possessed in 1969. This measure of health capital suffers from the defect that it depends on an individual's subjective evaluation of the state of his health: what one person considers to be excellent health may be viewed as good or only fair health by another. Moreover, it is not immediately obvious how to quantify the four possible responses. That is, one must determine exactly how much more health capital a man in, say, excellent health has compared to a man in poor health.

Table 1 contains a frequency distribution of health status in 1969 for married men in the NBER-Thorndike sample. For comparative purposes, the table also contains a frequency distribution of this variable for white married men in a 1963 health interview survey conducted by the National Opinion Research Center (NORC) and the 
TABLE 1

Frequency Distributions of Health Status, Married Men

\begin{tabular}{lcc}
\hline \hline & \multicolumn{2}{c}{ Percentage Distribution } \\
\cline { 2 - 3 } Class & $\begin{array}{c}\text { NBER-Thorndike } \\
\text { Sample }\end{array}$ & $\begin{array}{c}\text { NORC } \\
\text { Sample }\end{array}$ \\
\hline Excellent & 59.51 & 48.54 \\
Good & 37.29 & 37.45 \\
Fair & 2.80 & 11.87 \\
Poor & 0.40 & 2.14 \\
\hline
\end{tabular}

a Sample size is 3,534 . Until Section V, all subsequent tables based on the NBER-Thorndike sample pertain to this sample size.

bample size is 1,028 .

Center for Health Administration Studies of the University of Chicago. The NORC sample is an area probability sample of the entire civilian noninstitutionalized population of the United States. ${ }^{34}$ Therefore, its white male members are much more representative of the population at large than the members of the NBER-Thorndike sample.

In the table, I show that most of the men in the NBER-Thorndike sample are in either good or excellent health. I also show that the level of health of these men is higher than that of men in the NORC sample. Approximately 97 per cent of the former sample report that their health is at least good. The corresponding figure in the latter sample is approximately 86 per cent.

In Table 2, I present relationships between self-rated health status and more objective measures of health for both samples. These relationships take the form of regressions of number of work-loss weeks due to illness, medical expenditures, or number of symptoms reported from a checklist of twenty common symptoms ${ }^{35}$ on three health status dummy variables ( $H S 1, H S 2$, and $H S 3$ ). The dummy variables are coded as follows: $H S 1=1$ if health status is good, fair, or poor;

\footnotetext{
${ }^{34}$ Data were obtained from 2,367 families containing 7,803 persons. For a complete description of the NORC sample, see Andersen and Anderson (1967). I do not employ it to study health-schooling relationships in this paper, because it has no data on past health and very limited data on third variables.

:3 Examples of these symptoms include persistent cough, swelling in joints, frequent backaches, unexplained loss of weight, and repeated pains in or near the heart.
} 


\section{TABLE 2}

Regressions of Work-Loss Weeks Due to Illness, Medical Expenditures, and Symptoms on Health Status Dummy Variables a

\begin{tabular}{|c|c|c|c|c|c|}
\hline \multirow[b]{2}{*}{ Dependent Variable } & \multirow[b]{2}{*}{ Intercept } & \multicolumn{3}{|c|}{ Regression Coefficient of: } & \multirow[b]{2}{*}{$R^{2}$} \\
\hline & & $H S 1$ & $H S 2$ & $H S 3$ & \\
\hline Work-loss weeks ${ }^{b}$ & .103 & $\begin{array}{r}.235 \\
(3.94)\end{array}$ & $\begin{array}{r}.571 \\
(3.23)\end{array}$ & $\begin{array}{r}8.019 \\
(16.55)\end{array}$ & .102 \\
\hline Work-loss weeks ${ }^{c}$ & .524 & $\begin{array}{r}.584 \\
(2.43)\end{array}$ & $\begin{array}{c}1.749 \\
(4.75)\end{array}$ & $\begin{array}{c}4.929 \\
(6.00)\end{array}$ & .106 \\
\hline Medical expenditures ${ }^{c}$ & 55.854 & $\begin{array}{c}61.235 \\
(4.85)\end{array}$ & $\begin{array}{c}75.231 \\
(3.89)\end{array}$ & $\begin{array}{r}49.089 \\
(1.14)\end{array}$ & .067 \\
\hline Symptoms $^{c}$ & .940 & $\begin{array}{r}.741 \\
(5.87)\end{array}$ & $\begin{array}{c}1.401 \\
(7.25)\end{array}$ & $\begin{array}{r}3.463 \\
(8.04)\end{array}$ & .224 \\
\hline
\end{tabular}

a $t$ ratios in parentheses. $R^{2}$ is the unadjusted coefficient of multiple determination.

b Regression based on the NBER-Thorndike sample.

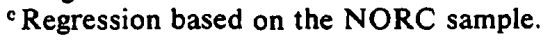

$H S 2=1$ if health status is fair or poor; and $H S 3=1$ if health status is poor. All three dependent variables pertain to the year preceding the survey.

Since there are no data on medical expenditures or symptoms in the NBER-Thorndike sample, only the first regression in Table 2 is relevant for this sample. It shows that the number of work-loss weeks in 1968 rises as health status declines. The intercept of the regression indicates that the mean number of work-loss weeks for men in excellent health equals .1. The regression coefficient of $H S 1$ indicates that men in good health have .2 more work-loss weeks on the average than men in excellent health. Similarly, men in fair health have .6 more workloss weeks than men in good health, and men in poor health have 8.0 more work-loss weeks than men in fair health. These differences in work-loss by health status are statistically significant at all conventional levels of confidence.

The second regression in Table 2 demonstrates a similar inverse relationship between work-loss and health status in the NORC sample. The third and fourth regressions show that medical expenditures and symptoms rise as health status falls. The negative relationship between medical expenditures, an input into the production of health, 
and health can be traced to a positive correlation between medical care and the rate of depreciation on health capital. An increase in the rate of depreciation would cause the quantity of health capital demanded to fall. At the same time, the quantity of medical care demanded would rise if the price elasticity of demand for health capital were less than one. ${ }^{36}$

Taken together, the regression results in Table 2 give evidence that variations in self-rated health status reflect true variations in more objective measures of health. Additional considerations support the use of this variable as an index of health. Palmore (1969a, 1969b) reports that work satisfaction, itself an important correlate of self-rated health, and health status are key determinants of survival in a longitudinal sample of older persons. Rahe and Holmes (1965); Holmes and Masuda (1970); and Rahe (1972) find that physical illness is often associated with changes in life events that cause changes in mental well-being. Variations in mental well-being may cause current health status to vary but may affect work-loss and other measures of disability only with a long lag.

The first regression in Table 2 and the production function of healthy time given by equation 2 can be employed to select a set of scales for health status. The scaling scheme is based on the proposition that health capital, like knowledge capital, is a units-free measure of an existing stock. Setting this index equal to one for men in poor health, one could then express the amount of health capital of men in one of the other three categories relative to that of men in poor health. To be specific, if time is measured in weeks, then the production function of healthy time given by equation 2 implies

$$
52-h=W L W=B H^{-C}
$$

where $W L W$ denotes the number of work-loss weeks due to illness. Solve equation 13 for $H$ to obtain

$$
H=B^{1 / C} W L W^{-1 / C}
$$

and let $W L W_{P}, W L W_{F}, W L W_{G}$, and $W L W_{E}$ be mean work-loss of men in poor, fair, good, and excellent health. Then, to express the stock of health in an index number form with $H_{P}=1$, write $H_{F} / H_{P}=$ $\left(W L W_{P} / W L W_{F}\right)^{1 / C}$, et cetera.

According to regression 1 in Table 2, $W L W_{P} / W L W_{F}=9.82, W L W_{P} /$

${ }^{36}$ For a proof, see Grossman (1972b, pp. 16-19). Given the production function of healthy time specified in equation 2 , the price elasticity of demand for health capital is $\epsilon=1 /(1+C)$. This elasticity is smaller than one since $C$ exceeds zero. 
$W L W_{G}=26.41$, and $W L W_{P} / W L W_{E}=86.68$. Thus, the health capital series, termed $H 69$ in subsequent analysis, is $1.00,9.82,26.41$, and 86.68. The dependent variable in the demand curve for adults' health should be $\ln H_{J} / H_{P}(J=P, F, G, E)$. Therefore, the use of $\ln W L W_{P} /$ $W L W_{J}$ as the dependent variable would generate regression coefficients that would exceed, equal, or fall short of the true coefficients as $C$ exceeds, equals, or falls short of one. However, because $C$ is a constant, the $t$ ratios associated with these coefficients would be unaffected.

In most of my empirical analysis in the next two sections, I emphasize the qualitative effects of independent variables on H69. To examine the sensitivity of results to the scaling scheme, I estimate some equations with a dichotomous dependent variable (EXCELL) that is equal to one if a man is in excellent health and is equal to zero otherwise. In a few instances, I discuss quantitative effects in conjunction with $H 69$, and in these instances, I assume that $C$ is equal to one. Of course, the quantitative analysis is based on the specification of the production function of healthy time given by equation 13. This specification is not the only one that is consistent with diminishing marginal productivity to health capital and an upper asymptote of 52 healthy weeks in a year, but it is the most simple one. I have investigated the behavior of the health capital series with more complicated functional forms such as the logistic function. Provided that the mean number of work-loss weeks for the entire sample and the mean for men in poor health are relatively small, this series is almost unaffected ${ }^{37}$ The existence of other functional forms and the somewhat arbitrary assumption about the value of $C$ does suggest, however, that quantitative results should be interpreted with caution.

I could have employed the actual number of work-loss weeks reported by an individual as a negative measure of health, but only 9 per cent of the NBER-Thorndike sample reported positive work-loss in $1968{ }^{38}$ Undoubtedly, there is a large random component in workloss in a given year. Therefore, it is reasonable to associate variations

${ }^{37}$ These two means are small in the NBER-Thorndike sample: 3 weeks for the entire sample and 9.8 weeks for men in poor health.

${ }^{38}$ The corresponding figure in the NORC sample is 33 per cent. Although part of this difference reflects the higher level of health in the NBER-Thorndike sample, part of it is due to the manner in which the work-loss data were collected. The members of the NORC sample were asked for work-loss days, while the members of the NBERThorndike sample were asked for work-loss weeks. The mean number of work-loss days in the NORC sample is 5 , and many persons reported 1 to 4 days. Therefore, at least some of the zero values in the NBER-Thorndike sample may represent positive amounts of work-loss days. This is another reason why I do not use work-loss itself as a measure of health. 
in work-loss due to variations in health status with "permanent" differences in health. On the other hand, variations in work-loss not accounted for by variations in health status may be viewed as more "transitory" in nature.

The 1971 NBER-Thorndike resurvey contains a proxy variable for past health. The men in the sample were asked whether the state of their health during the years they were attending high school was excellent, good, fair, or poor. The frequency distribution of responses is as follows: excellent, 87.29 per cent; good, 11.72 per cent; fair, 0.88 per cent; and poor, 0.11 per cent. The men were also asked how many weeks per year they lost from high school, on the average, due to illness. I analyze the relationship between self-rated high-school health status and average school-loss weeks due to illness $(S L W)$ in the same manner as I analyzed the relationship between current health status and work-loss weeks. Specificaliy, I estimate a regression of $S L W$ on three dummy variables for high-school health status: $H S H S 1$ $=1$ if high-school health status is good, fair, or poor; $H S H S 2=1$ if high-school health status is fair or poor; and $H S H S 3=1$ if high-school health status is poor. The regression is as follows ( $t$ ratios in parentheses):

$$
\begin{gathered}
S L W=.403+.384 H S H S 1+.907 H S H S 2+1.306 H S H S 3 \\
(15.04) \\
(10.00)
\end{gathered}
$$

Based on this regression, I create a series for health capital in high school the same way that I created a series for health capital in 1969. Let $S L W_{P}, S L W_{F}, S L W_{G}$, and $S L W_{E}$ be mean school-loss of students in poor, fair, good, and excellent health. According to the regression, $S L W_{P} / S L W_{F}=1.77, S L W_{P} / S L W_{G}=3.81$, and $S L W_{P} / S L W_{E}=7.44$. Thus, the past or high-school health capital series, termed $H H S$ in subsequent analysis, is $1.00,1.77,3.81$, and 7.44 . This measure of past health suffers from the defect that it was obtained in a retrospective fashion. Note, however, that the information on current health was requested in 1969, while the information on past health was requested in 1971. Since the two variables were obtained at different points in time, the possibility of a spurious positive correlation between them is greatly mitigated. That is, respondents could not have used their answer to a question on current health status as the basis for an answer to a question on past health status. 


\section{Regression Specification}

The most general versions of the health and schooling regressions that I estimate with the NBER-Thorndike sample are given by

$$
\begin{array}{r}
\ln H 69=b_{1} A+b_{2} S+b_{3} S F A T+b_{4} S M O T+b_{5} V+b_{6} P \\
+b_{7} M E C H+b_{8} N U M+b_{9} G E N+b_{10} \ln H H S+b_{11} S W I F E \\
+b_{1 \cdot 2} J S A T+b_{13} W T D I F+b_{14} \ln W+b_{15} O T I N C \\
\begin{array}{r}
S=a_{1} A+a_{2} S F A T+a_{3} \\
S M O T+a_{4} V+a_{5} P+a_{6} M E C H \\
+a_{7} N U M+a_{8} G E N+a_{9} \ln H H S
\end{array}
\end{array}
$$

\begin{tabular}{|c|c|}
\hline Variable & Definition \\
\hline $\ln H 69$ & Natural logarithm of stock of health in 1969 a \\
\hline$A$ & Age in 1969 \\
\hline$S$ & Years of formal schooling completed \\
\hline$S F A T$ & Years of formal schooling completed by father \\
\hline$S M O T$ & Years of formal schooling completed by mother \\
\hline $\boldsymbol{V}$ & Visual perception ${ }^{a}$ \\
\hline$P$ & Psychomotor control ${ }^{a}$ \\
\hline$M E C H$ & Mechanical ability a \\
\hline$G E N$ & General intelligence a \\
\hline$N U M$ & Numerical ability a \\
\hline $\ln H H S$ & $\begin{array}{l}\text { Natural logarithm of stock of health while attending } \\
\text { high school a }^{\text {high }}\end{array}$ \\
\hline$S W I F E$ & Years of formal schooling completed by wife \\
\hline$J S A T$ & Job satisfaction: $1=$ lowest; $5=$ highest $^{a}$ \\
\hline$W T D I F$ & $\begin{array}{l}\text { Weight difference: absolute value of difference be- } \\
\text { tween actual weight and ideal weight for a given } \\
\text { height }^{\text {a }}\end{array}$ \\
\hline $\ln W$ & Natural logarithm of hourly wage rate on current job a \\
\hline OTINC & Nonearnings income of the family in 1968 \\
\hline EXCELL & Excellent health in $1969=1^{b}$ \\
\hline
\end{tabular}

Table 3 contains definitions of the variables in these two regressions, Table A.1 in the appendix contains their means and standard devia-

TABLE 3

Definition of Variables, NBER-Thorndike Sample

a See text for a more complete definition.

bee Section III for a discussion of the use of this variable. 
tions, and Table A. 2 contains a matrix of simple correlation coefficients. All variables except past health, mothers' schooling, and the test scores are taken from the 1969 survey. Mothers' schooling and past health are taken from the 1971 survey, and the 1943 test scores are taken from military records. I formulated specific hypotheses concerning the roles of most of the right-hand side variables in equations 15 and 16 in Section $\mathbf{l}$. Therefore, in the remainder of this section, I clarify a few of the definitions in Table 3 and comment on the predicted effects of several variables that I did not discuss in Section I.

The hourly wage rate equals a man's full-time salary on his current job divided by the product of fifty weeks and the average number of hours per week he worked on his main job in 1968. The five ability variables $(V, P, M E C H, G E N, N U M)$ are derived from Thorndike and Hagan's factor analysis (1959, p. 19) of scores on the seventeen specific tests that candidates for Aviation Cadet status were given in 1943. Based on their analysis, Thorndike and Hagan identified the five basic types of ability given in Table 3. The tests included in each of these categories are listed in Table 4.

I generate an aggregate index of visual perception, for example, by computing the first principal component of its three test scores, where each score is normalized to have a zero mean and a unitary standard deviation. Specifically, if $X_{i}(i=1,2,3)$ denotes the normalized value of the $i$ th test score included in visual perception, then $V=\sum_{i=1}^{3} a_{i} X_{i}$, where the $a_{i}$ are selected to maximize the variance in $V$ subject to the constraint that $\sum_{i=1}^{3} a_{i}{ }^{2}=1 .{ }^{39}$ I follow a similar procedure to aggregate the scores in the other four categories. One justification for my procedure is that the units in which ability is measured are arbitrary. It should be noted that health functions estimated with, for example, visual perception defined as a simple average of its three test scores (not shown) do not differ in a qualitative sense from those estimated with the principal components measures in the next section.

When the men in the NBER-Thorndike sample took the seventeen tests in 1943, practically all of them had graduated from high school but had little additional schooling. Most of those who went on to college did so after World War II. Thus, in this data set, one largely avoids the problem that a person's performance on a general intelli-

\footnotetext{
${ }^{39}$ The $a_{i}$ coincide with the elements of the characteristic vector associated with the largest characteristic root of the correlation matrix of the $X_{i}$.
} 
TABLE 4

Categories of Ability

\begin{tabular}{|c|c|}
\hline Category & Tests Included a \\
\hline Visual Perception & $\begin{array}{l}\text { Speed of Identification } \\
\text { Spatial Orientation I } \\
\text { Spatial Orientation II }\end{array}$ \\
\hline Psychomotor Control & $\begin{array}{l}\text { Complex Coordination } \\
\text { Rotary Pursuit } \\
\text { Finger Dexterity } \\
\text { Aiming Stress }\end{array}$ \\
\hline Mechanical Ability & $\begin{array}{l}\text { Mechanical Principles } \\
\text { Two-Hand Coordination } \\
\text { Biographical Data-Pilot }{ }^{\text {b }}\end{array}$ \\
\hline General Intelligence & $\begin{array}{l}\text { Reading Comprehension } \\
\text { General Information-Navigator }{ }^{c} \\
\text { Arithmetic Reasoning } \\
\text { Mathematics }\end{array}$ \\
\hline Numerical Ability & $\begin{array}{l}\text { Numerical Operations I } \\
\text { Numerical Operations II } \\
\text { Dial and Table Reading }\end{array}$ \\
\hline
\end{tabular}

a For a description of each test. see Thorndike and Hagen (1959, pp. 55-76).

${ }^{b}$ Items on a biographical data form that proved to be important predictors of performance in pilot training school of candidates who were accepted as Pilot Aviation Cadets.

' A vocabulary test that dealt with terminology in astronomy, trigonometry, and science.

gence test will depend on the amount of schooling he has had. A small percentage of the men, chiefly the older ones, did attend college prior to World War II. Moreover, high-school graduates who participated in the labor force for several years before the war might have scored lower on the general intelligence tests than recent high-school graduates. To eliminate a potential reverse causality relationship running from schooling to general intelligence, I include age in the schooling function. Due to the upward secular trend in years of formal schooling completed, age and schooling are negatively correlated in random samples of the population of the United States. This negative correla- 
tion is also present in the NBER-Thorndike sample $(r=-.172)$ despite the narrow age range of the sample. Therefore, by including age in the schooling function, I control for the trend factor and avoid biasing the estimated effect of intelligence on schooling.

There are two reasons for employing a measure of job satisfaction as an independent variable in the health function. First, someone who is satisfied with his job and with his life style in general may also be more satisfied with the state of his health than someone who is dissatisfied with his job and life style. Thus, the first person may be more likely to report that his health status is good or excellent, even though the two persons may have the same level of physical health measured in an objective fashion. Consequently, by holding job satisfaction constant, I purge self-rated health status of some of its subjective elements. Second, the studies that I have already cited by Rahe and Holmes (1965); Palmore (1969a, 1969b); Holmes and Masuda (1970); and Rahe (1972) indicate that dissatisfaction with life style creates tensions that cause mental and ultimately physical health to deteriorate. In this context, Palmore's finding that job satisfaction is the most important correlate of longevity in a longitudinal sample of older persons is particularly striking. Along these lines, one can view job satisfaction as an input into the production of health and estimate the sensitivity of health output to variations in this input.

The men in the NBER-Thorndike sample were asked whether they enjoy their work, whether their work provides a challenge, and whether their work is interesting. Each question has five possible numerical responses that constitute a scale ranging from five (the highest) to one (the lowest). The job-satisfaction index that $I$ use is simply an average of a man's responses to these three questions.

Obesity and malnutrition, like job satisfaction, may be treated as inputs into the production of health. By computing the absolute value of the difference between actual weight and ideal weight for a given height, I create one variable to measure these mutually exclusive states. The 1969 questionnaire included items on actual height and actual weight. I calculate ideal weight for a given height from estimates made by the Metropolitan Life Insurance Company. ${ }^{40}$ These estimates take the form of ideal weights for men by height and body frame (small, medium, or large). Since there is no information on body frames of men in the NBER-Thorndike sample, I define ideal weight for a given height as an average of the weight given for each body frame.

${ }^{40}$ These estimates are reported by Netzer $(1969$, p. 129). 


\section{The Correlation between Health and Schooling 175}

The inclusion of two input variables, job satisfaction and weight difference, in the health function makes this function a mixture of a demand curve and a production function. If most of the variation in job satisfaction and weight difference were due to variation in the "prices" of these inputs, the estimated equation would be primarily a demand curve for health. ${ }^{41}$ Under this interpretation, nonearnings income would enter the health function to take account of the pure consumption aspects of the demand for health. Alternatively, the wage rate and nonearnings income can be viewed as proxies for inputs besides job satisfaction and weight difference that affect health. Under this interpretation, the estimated equation would be primarily a production function of health. I do not emphasize one of these two extreme interpretations of the health function in the next section. I do, however, examine the extent to which the productivity effect of schooling on health operates via the impact of schooling on contemporaneous variables such as job satisfaction and weight difference.

\section{EMPIRICAL RESULTS}

\section{A. Estimates of Recursive Health-Schooling System}

Table 5 contains ordinary least squares estimates of health functions, and Table 6 contains corresponding estimates of schooling functions. The empirical analysis reflected by the regressions in these two tables represents a compromise between rigorous hypothesis testing of the effects of given variables and attempts to come to grips with somewhat more broad issues. These issues include the answers to such questions as: Which components of ability are the major determinants of health or schooling? By how much is the estimated effect of schooling on current health biased when past health and third variables are omitted from the health function? Do contemporaneous variables such as wives' schooling, job satisfaction, weight difference, the hourly wage rate, and nonearnings income play a more important role in the health function than lagged variables such as parents' schooling, ability in 1943 , and past health? Does the inclusion of the set of lagged variables have a greater impact on the coefficient of own schooling than the in-

\footnotetext{
${ }^{41}$ Admittedly, it would be difficult to define these input prices, although elsewhere (Grossman 1971) I have shown that the concept and theory of joint production would aid in accomplishing this task. The price of job satisfaction might be defined as the reduction in the wage rate required to increase this variable by one unit, with schooling held constant. But the partial correlation between job satisfaction and the wage is positive in the NBER-Thorndike sample possibly because the "income effect" dominates the "substitution effect."
} 
TABLE 5

Ordinary Least Squares Estimates of Health Functions a

\begin{tabular}{|c|c|c|c|c|c|c|c|}
\hline & Eq. 1 & Eq. 2 & Eq. 3 & Eq. 4 & Eq. 5 & Eq. 6 & Eq. 7 \\
\hline Variable & $\begin{array}{l}\text { Regr. } \\
\text { Coef. }\end{array}$ & $\begin{array}{l}\text { Regr. } \\
\text { Coef. }\end{array}$ & $\begin{array}{l}\text { Regr. } \\
\text { Coef. }\end{array}$ & $\begin{array}{l}\text { Regr. } \\
\text { Coef. }\end{array}$ & $\begin{array}{l}\text { Regr. } \\
\text { Coef. }\end{array}$ & $\begin{array}{l}\text { Regr. } \\
\text { Coef. }\end{array}$ & $\begin{array}{l}\text { Regr. } \\
\text { Coef. }\end{array}$ \\
\hline$A$ & $\begin{array}{l}-.017 \\
(-3.31)\end{array}$ & $\begin{array}{l}-.012 \\
(-2.33)\end{array}$ & $\begin{array}{l}-.011 \\
(-2.07)\end{array}$ & $\begin{array}{l}-.011 \\
(-2.14)\end{array}$ & $\begin{array}{l}-.010 \\
(-1.92)\end{array}$ & $\begin{array}{l}-.010 \\
(-2.00)\end{array}$ & $\begin{array}{l}-.011 \\
(-2.17)\end{array}$ \\
\hline$S$ & $\begin{array}{c}.035 \\
(7.41)\end{array}$ & $\begin{array}{c}.028 \\
(5.51)\end{array}$ & $\begin{array}{c}.028 \\
(5.94)\end{array}$ & $\begin{array}{c}.019 \\
(3.76)\end{array}$ & $\begin{array}{c}.019 \\
(3.92)\end{array}$ & $\begin{array}{c}.012 \\
(2.26)\end{array}$ & $\begin{array}{c}.012 \\
(2.26)\end{array}$ \\
\hline$S F A T$ & & $\begin{array}{c}.005 \\
(1.51)\end{array}$ & $\begin{array}{c}.006 \\
(1.58)\end{array}$ & $\begin{array}{c}.004 \\
(1.00)\end{array}$ & $\begin{array}{c}.004 \\
(1.23)\end{array}$ & $\begin{array}{c}.003 \\
(0.72)\end{array}$ & $\begin{array}{c}.002 \\
(0.65)\end{array}$ \\
\hline$S M O T$ & & $\begin{array}{c}.006 \\
\text { (1.57) }\end{array}$ & $\begin{array}{c}.007 \\
(1.87)\end{array}$ & $\begin{array}{c}.005 \\
(1.30)\end{array}$ & $\begin{array}{c}.006 \\
(1.73)\end{array}$ & $\begin{array}{c}.004 \\
(1.21)\end{array}$ & $\begin{array}{c}.003 \\
(0.94)\end{array}$ \\
\hline$V$ & & $\begin{array}{c}.027 \\
(2.81)\end{array}$ & $\begin{array}{c}.036 \\
(4.19)\end{array}$ & $\begin{array}{c}.035 \\
(4.19)\end{array}$ & $\begin{array}{c}.033 \\
(3.87)\end{array}$ & $\begin{array}{c}.033 \\
(3.91)\end{array}$ & $\begin{array}{c}.027 \\
(2.86)\end{array}$ \\
\hline$P$ & & $\begin{array}{c}.010 \\
(1.02)\end{array}$ & & & & & $\begin{array}{c}.008 \\
(0.83)\end{array}$ \\
\hline$M E C H$ & & $\begin{array}{c}.012 \\
(1.16)\end{array}$ & & & & & $\begin{array}{c}.013 \\
(1.26)\end{array}$ \\
\hline$N U M$ & & $\begin{array}{c}.004 \\
(0.42)\end{array}$ & & & & & $\begin{array}{c}-.001 \\
(-0.12)\end{array}$ \\
\hline$G E N$ & & $\begin{array}{c}.005 \\
(0.60)\end{array}$ & & & & & $\begin{array}{c}.002 \\
(0.27)\end{array}$ \\
\hline $\ln H H S$ & & $\begin{array}{c}.479 \\
(11.05)\end{array}$ & $\begin{array}{c}.481 \\
(11.12)\end{array}$ & $\begin{array}{c}.461 \\
(10.74)\end{array}$ & $\begin{array}{c}.459 \\
(10.66)\end{array}$ & $\begin{array}{c}.445 \\
(10.39)\end{array}$ & $\begin{array}{c}.445 \\
(10.37)\end{array}$ \\
\hline SWIFE & & & & $\begin{array}{c}.019 \\
(3.25)\end{array}$ & & $\begin{array}{c}.018 \\
(3.16)\end{array}$ & $\begin{array}{c}.018 \\
(3.16)\end{array}$ \\
\hline$J S A T$ & & & & $\begin{array}{c}.094 \\
(6.67)\end{array}$ & & $\begin{array}{c}.082 \\
(5.76)\end{array}$ & $\begin{array}{c}.082 \\
(5.72)\end{array}$ \\
\hline$W T D I F$ & & & & $\begin{array}{l}-.002 \\
(-3.57)\end{array}$ & & $\begin{array}{c}-.002 \\
(-3.52)\end{array}$ & $\begin{array}{c}-.002 \\
(-3.41)\end{array}$ \\
\hline $\ln W$ & & & & & $\begin{array}{c}.167 \\
(7.00)\end{array}$ & $\begin{array}{c}.146 \\
(6.10)\end{array}$ & $\begin{array}{c}.147 \\
(6.05)\end{array}$ \\
\hline OTINC & & & & & $\begin{array}{l}-.001 \\
(-0.29)\end{array}$ & $\begin{array}{l}-.0005 \\
(-0.28)\end{array}$ & $\begin{array}{c}-.001 \\
(-0.30)\end{array}$ \\
\hline$R^{2}$ & .021 & .064 & .063 & .080 & .076 & .090 & .091 \\
\hline
\end{tabular}

a Intercepts not shown. $t$ ratios in parentheses. See Table 3 for definitions of all varibles. 


\section{The Correlation between Health and Schooling 177}

TABLE 6

Ordinary Least Squares Estimates of Schooling Functions ${ }^{\text {a }}$

\begin{tabular}{lccc}
\hline \hline & Equation 1 & Equation 2 & Equation 3 \\
\cline { 2 - 4 } Variable & $\begin{array}{c}\text { Regression } \\
\text { Coefficient }\end{array}$ & $\begin{array}{c}\text { Regression } \\
\text { Coefficient }\end{array}$ & $\begin{array}{c}\text { Regression } \\
\text { Coefficient }\end{array}$ \\
\hline$A$ & -.146 & -.124 & -.131 \\
SFAT & $(-8.40)$ & $(-7.08)$ & $(-7.58)$ \\
& .067 & .066 & .067 \\
$S M O T$ & $(5.47)$ & $(5.52)$ & $(5.61)$ \\
$V$ & .032 & .050 & .050 \\
& $(2.56)$ & $(4.03)$ & $(4.05)$ \\
$P$ & & .052 & .030 \\
& & $(1.65)$ & $(1.00)$ \\
$M E C H$ & & .004 & \\
$N U M$ & & $(0.11)$ & -.318 \\
& & -.339 & $(-10.30)$ \\
$G E N$ & & $(-9.98)$ & \\
In $H H S$ & & -.082 & .499 \\
$R^{2}$ & .446 & $(-2.62)$ & $(19.94)$ \\
& $(18.40)$ & .534 & .396 \\
& .419 & $(18.85)$ & $(2.74)$ \\
& $(2.86)$ & .416 & .171 \\
\hline
\end{tabular}

a $t$ ratios in parentheses.

clusion of the set of current variables? Which of the contemporaneous variables have the most significant effects on health and on the estimated coefficient of schooling? Which of the lagged variables influence health only indirectly, via their effects on schooling?

To examine these issues, in Tables 5 and 6, I show alternative versions of health and schooling equations. In addition, in Table 7, I show the percentage reduction in the coefficient of schooling when specific sets of variables are held constant. ${ }^{42} \mathrm{My}$ discussion of the regression results is organized as follows. First, I comment on variations in the

42 The computations in Table 7 are based on the regressions in Table 5, as well as on some additional regressions not shown in the table. These computations do not depend on the value of the parameter $C$ in the production function of healthy time given by equation 2 or equation 13 . 


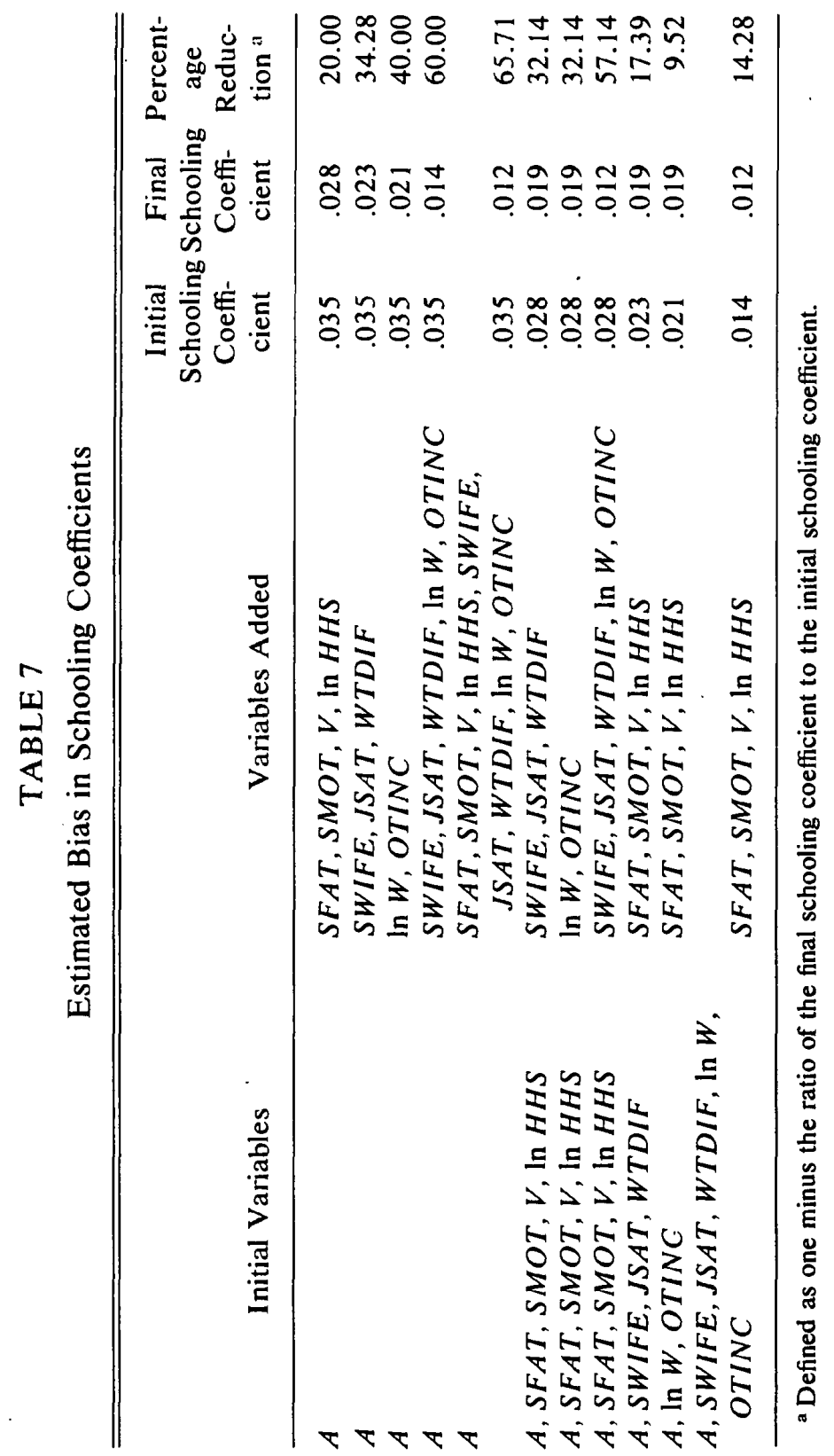


estimated schooling parameter in the health function as the set of independent variables varies. Then, I examine some specific health effects of current variables other than schooling. Finally, I discuss health effects of past variables and the roles of these variables in the schooling equation. ${ }^{43}$

Regardless of the other variables held constant, schooling has a positive effect on current health that is statistically significant at the .025 level of confidence on a one-tail test. Since past health is included in each equation in Table 5 except the first, this finding may be interpreted as evidence in favor of a causal relationship that runs from schooling to current health. The actual regression coefficients indicate the continuously compounded percentage rate of increase in health capital associated with a one-year increase in schooling. These coefficients range from 3.5 per cent, when only age is held constant, to 1.2 per cent, when all relevant variables are held constant.

Suppose that the health functions were viewed primarily as demand curves, and suppose that the price elasticity of demand for health were equal to one-half. Then the schooling parameter estimates would imply that schooling raises health productivity by 2.4 per cent at a minimum. ${ }^{44}$ This may be compared to the approximately 5.5 per cent increase in the hourly wage rate due to an additional year of formal schooling in the NBER-Thorndike sample. ${ }^{45}$ Although the nonmarket productivity effect of schooling may appear to be small in an absolute sense, it is approximately 40 per cent as large as the market productivity effect. Moreover, in assessing the magnitude of the effect, it should be realized that all of the men in the sample are high-school graduates. If the nonmarket productivity improvement falls as schooling rises, then my estimate would understate the effect that would be observed in a sample of men at all schooling levels.

In Table 7, I reveal that the estimated bias in schooling coefficients is larger when current variables are excluded from the health function

${ }^{43} \mathrm{My}$ empirical analysis in parts $\mathrm{A}$ and $\mathrm{B}$ of this section is similar to Griliches and Mason's (1972) analysis of interrelationships among schooling, ability, and earnings.

${ }^{44}$ The price elasticity of health would equal one-half if $C$ in the production function of healthy time given by equation 2 or 13 were equal to one. According to the reduced form demand curve for health given by equation $9^{\prime \prime}$, the schooling parameter should be $c_{1} \rho \epsilon$, where $c_{1}$ gives the effect of schooling on the stock of human capital. My estimate of $\rho$ assumes that $c_{1}$ equals one, but this assumption would not affect the comparison of market and nonmarket productivity effects:

${ }^{45}$ This figure is based on a regression of the natural logarithm of the hourly wage rate on schooling, years of experience in the labor force, general intelligence, and several other variables. 
than when past variables are excluded. For example, the estimated bias due to the omission of parents' schooling, visual perception, and past health is 20 per cent (line 1 of Table 7) ${ }^{46}$ The corresponding bias due to the omission of wives' schooling, weight difference, job satisfaction, the wage rate, and nonearnings income is 60 per cent (line 4). When past variables are held constant initially but current variables are not, the bias is 57 per cent (line 8). When this procedure is reversed, the bias is only 14 per cent (line 11 ). These results arise because the set of current variables is more highly correlated with schooling than the set of past variables.

In Table 7, I also reveal that the bias from omitting the subset of contemporaneous variables consisting of wives' schooling, job satisfaction, and weight difference is approximately the same as the bias that arises from omitting the subset consisting of the wage rate and nonearnings income. In particular, when past variables are included in the regressions, the bias due to the exclusion of each subset is 32 per cent (lines 6 and 7). This is an important finding if one is seeking to uncover channels via which the pure effect of schooling on nonmarket productivity operates. If one does not control for any of the contemporaneous variables, then schooling may increase health simply because it raises market productivity and therefore command over market resources. If one takes account of this factor by holding the wage rate and nonearnings income constant, then part of the remaining effect of schooling on health may operate via the effect of this variable on spouses' characteristics, satisfaction with life style, and diet.

According to equation 6 or 7 in Table 5, with the wage rate and nonearnings income held constant, an increase in wives' schooling, an increase in job satisfaction, or a reduction in the absolute value of the difference between actual and ideal weight causes health to rise. The regression coefficients of these three variables are statistically significant at all conventional levels of confidence. The effect of wives' schooling is striking, because the coefficient of this variable exceeds the coefficient of own schooling. The difference between these two coefficients is not, however, statistically significant $(t=.68$ in both equations).

Even if the coefficients of husbands' and wives' schooling were the same, provided that the estimated health functions primarily reflected

\footnotetext{
${ }^{46}$ The other test scores are omitted from the computations in Table 7, because they have statistically insignificant effects on health. This procedure is justified in more detail when the effects of third variables are discussed below.
} 
demand forces, one could conclude that wives' schooling has a larger impact on the efficiency with which husbands' health is produced than husbands' schooling. Since there is no specific measure of the value of wives' time, the demand parameter of their schooling would equal $\epsilon\left(\rho_{f}-\alpha_{f} \hat{W}_{f}\right)$, where $\epsilon$ is the price elasticity of health, $\rho_{f}$ is the percentage increase in wives' nonmarket productivity for a one-year increase in schooling, $\alpha_{f}$ is the share of wives' time in the total cost of gross investment in husbands' health, and $\hat{W}_{f}$ is the percentage increase in the "shadow price" of time due to schooling. On the other hand, since husbands' wage rates are held constant, the demand parameter of their schooling should equal $\epsilon \rho$, where $\rho$ is the percentage increase in their nonmarket productivity due to schooling. If these two demand parameters are identical, then

$$
\rho_{f}=\rho+\alpha_{f} \hat{W}_{f}
$$

Heckman in "Shadow Prices, Market Wages, and Labor Supply," 47 estimates that a one-year increase in wives' schooling raises the shadow price of time by 5.3 per cent, and $I$ have already estimated that $\rho$ equals 2.4 per cent. Therefore, $\rho_{f}$ would equal 3.7 per cent if $\alpha_{f}$ were onequarter, and would equal 5.0 per cent if $\alpha_{r}$ were one-half.

An alternative explanation of the effect of wives' schooling is that it reflects selective mating in the marriage market. ${ }^{48}$ According to this interpretation, healthier men marry women with more schooling. Yet I control for important correlates of selective mating, such as general intelligence, parents' schooling, and past health..$^{49}$ Therefore, it is very unlikely that a significant part of the relationship between wives' schooling and husbands' health can be traced to selective mating.

With regard to the other contemporaneous variables, age is negatively related to health, which reflects the positive impact of this variable on the rate of depreciation on health capital. The hourly wage rate has a positive and very significant effect on health, while nonearnings income has an insignificant negative effect. These two findings support the predictions of my pure investment model of the demand for health. In a production function sense, the weak negative coefficient of nonearnings income may represent a compromise

${ }^{47}$ Econometrica 42 (July 1974):679-694.

${ }^{48}$ See Becker (1973) for a general discussion of the economics underlying this phenomenon and Fuchs (1974) for a discussion of health differentials among married men in terms of selective mating and other factors.

${ }^{49}$ Welch (1974) criticizes Benham (1974) for measuring the effect of wives' schooling on husbands' market productivity without controlling for husbands' ability and background characteristics. 
between the consumption of beneficial and detrimental health inputs as income rises, with the wage rate held constant. Clearly this interpretation should not be pushed too far because the coefficient of nonearnings income is not statistically significant. But it may appeal to those who are surprised to learn that the pure income elasticity of health ranges from -.01 to -.02 at an income of $\$ 20,000 .{ }^{50}$

As shown by the $t$ ratios associated with the regression coefficients of past health in Table 5, the partial correlation between this variable and current health exceeds the partial correlation between current health and any of the other independent variables in the regressions. The elasticity of current health with respect to past health varies from .44 to .48 . In a demand-curve sense, this elasticity should estimate the ratio of the price elasticity of adults' health to the price elasticity of children's health. ${ }^{51}$ Since the coefficient of $\ln H H S$ is smaller than one, the demand curve for children's health is more elastic than the demand curve for adults' health. If, as I have assumed in other computations, the price elasticity of adults' health equals one-half, then the price elasticity of children's health would approximately equal one.

The equations in Table 6 demonstrate that although past health is certainly not the most important determinant of schooling, it does have a statistically significant positive effect on years of formal schooling completed. Despite this, and despite the important role of past health in the current health function, the parameter estimate of schooling is not greatly affected by the inclusion of past health. This follows because schooling and past health are not nearly as highly correlated as schooling and the set of current variables. If the past health parameter estimate in the schooling function and the schooling parameter estimate in the health function are both converted into elasticities, then the elasticity of schooling with respect to past health would equal .03 and the elasticity of current health with respect to schooling would equal .18. It is clear that the latter elasticity dominates the former.

According to equation 7 in Table 5, among the past variables other than health in high school, only visual perception has a statistically significant effect on current health when all relevant factors are held constant. According to equation 2, this is true even if the set of predictor variables is limited to age, schooling, parents' schooling, the

\footnotetext{
${ }^{50}$ The pure income elasticity is computed as the product of the regression coefficient of nonearnings income ( $\partial$ ln $H 69 / \partial O T I N C)$ and total income in thousands of dollars.

${ }^{31}$ See equation $9^{\prime \prime}$.
} 
test scores, and past health. ${ }^{52}$ As the equations in Table 6 reveal, parents' schooling and general intelligence are important determinants of schooling. Therefore, my results suggest that the effects of these variables on current health operate indirectly, via their effects on schooling. Once schooling is held constant, they have almost no direct impact on health.

In Section I, I argued that given the health-specific nature of physical ability, it should have a larger impact on current health than does mental ability. On the other hand, given the schooling-specific nature of mental ability; it should have a larger impact on schooling than does physical ability. Tables 5 and 6 contain some evidence in support of this hypothesis, provided visual perception is interpreted as a measure of health-specific ability and general intelligence is interpreted as a measure of schooling-specific ability. In interpreting the positive effect of visual perception on current health in this manner, I do not necessarily assume that this variable per se has a direct impact on current health. Rather, I assume that it is the best available proxy for genetic or biological characteristics that do influence the efficiency with which health is produced. ${ }^{53}$

Based on the above argument, and given that visual perception is the only component of ability that has a positive effect on health, I prefer a regression specification of the health function that omits the four other ability variables. Another reason for preferring such a specification is that, with general intelligence and parental characteristics held constant, it is not obvious what causes schooling to vary. ${ }^{54}$ Since general intelligence plays a very important role in the estimated schooling function and plays an unimportant role in the estimated health function, it is logical to exclude it from the latter function. In theory, the appropriate way to take account of the insignificant effects of the four ability variables would be to reestimate the health function with another

${ }^{52}$ The simple correlation coefficient between fathers' schooling and mothers' schooling is .467 . If either of these two variables is excluded from the set of independent variables, the remaining one is statistically significant in equation 2 , borders on significance in several other equations in Table 5, but is not significant in equation 7. For this reason, I include both variables in the estimates of biases in schooling coefficients in Table 7.

${ }^{33}$ In this context, note that two of the scores in the mechanical ability component measure knowledge of mechanical principles rather than mechanical ability in a physical sense. Since persons may have acquired this knowledge in the labor force prior to 1943 , the large negative effect of mechanical ability on schooling may be spurious.

${ }^{54}$ One source of variation may be traced to complementarity between number of years of schooling completed and the quality of schooling. 
sample. Since this is not a feasible course of action at the present time, I omit these variables from the empirical analysis in the rest of this section and in Section IV.

\section{B. Decomposition Analysis}

It is well established that schooling raises market productivity, and my results in part $\mathrm{A}$ of this section suggest that it raises health productivity as well. Indeed, the recent work on the household production function approach to demand theory emphasizes the pervasive impact of schooling on many aspects of consumer behavior, including fertility, contraceptive knowlege, efficiency in producing quality children, and consumption patterns. ${ }^{55}$ If schooling enhances productivity and knowledge in many areas, then it should increase a person's knowledge about an appropriate diet and raise his or her ability to select a productive mate and to produce a "high quality life style." Therefore, with market productivity, measured by the wage rate, and past variables held constant, the,effect of schooling on health may be decomposed into direct and indirect components. The direct component represents the ability of those with additional schooling to obtain a larger health output from given amounts of all relevant inputs. The indirect component represents the ability of those with extra schooling to select a better input mix..$^{56}$

In Table 8, I decompose an estimate of a total nonmarket productivity effect of schooling on health of 1.9 per cent into a direct component of 1.2 per cent and an indirect component of 0.7 per cent. The total effect equals the regression coefficient of schooling in an equation that includes age, parents' schooling, visual perception, past health, the wage rate, and nonearnings income as independent variables. The direct component equals the regression coefficient of schooling in an equation that adds wives' schooling, weight difference, and job satisfaction to the set of independent variables. The three positive indirect components are present because an increase in husbands' schooling is associated with an increase in wives' schooling, an increase in job satisfaction, and a reduction in the absolute value of the difference between actual and ideal weight. In turn, each of these three factors causes current health to rise.

\footnotetext{
${ }^{55}$ See, for example, the references cited in the introductory section of this paper.

${ }^{56}$ This. decomposition is due to Welch (1970), who terms the direct component the "worker effect" and the indirect component the "allocative effect."
} 
TABLE 8

Estimates of Direct and First-Order Indirect Effects of Schooling on Health

\begin{tabular}{lcc}
\hline \hline Source of Effect & Magnitude & $\begin{array}{r}\text { Percentage of } \\
\text { Total Effect }\end{array}$ \\
\hline Direct a & .012 & 63.16 \\
First-order indirect: & & .005 \\
$\quad$ Wives' schooling & .001 & 26.32 \\
Job satisfaction & .001 & 5.26 \\
Weight difference & .019 & 5.26 \\
$\quad$ Total b & .00 .00 \\
\hline
\end{tabular}

a Regression coefficient of schooling from equation 6 in Table 5.

${ }^{\circ}$ Regression coefficient of schooling from equation 5 in Table 5.

The statistical model that underlies this decomposition is a recursive system of the form:

$$
\begin{aligned}
S W I F E & =a_{1} S+a_{2} Z \\
J S A T & =c_{1} S+c_{2} Z+c_{3} S W I F E \\
W T D I F & =d_{1} S+d_{2} Z+d_{3} S W I F E+d_{4} J S A T \\
\ln H 69 & =b_{1} S+b_{2} Z+b_{3} S W I F E+b_{4} J S A T+b_{5} W T D I F
\end{aligned}
$$

where $Z$ is a vector of predetermined variables. By substituting the first three equations into the fourth, one obtains an estimate of the total or reduced-form parameter of schooling. The direct component of this parameter estimate is given by $b_{1}$, the first-order indirect component due to wives' schooling by $a_{1} b_{3}$, the first-order indirect component due to job satisfaction by $c_{1} b_{4}$, and the first-order indirect component due to weight difference by $d_{1} b_{5}{ }^{57}$

In Table 8, I show that of the three indirect channels, the one due to wives' schooling is by far the most important. This channel accounts for 26.32 per cent of the total effect of husbands' schooling and 71.43 per cent of the combined indirect effect. Table 9 contains modified

\footnotetext{
${ }^{57}$ There are also second- and higher-order indirect effects that arise, for example, because wives' schooling influences job satisfaction. But these are extremely small and are not shown in Table 8. It may seem arbitrary to assume that the determination of $J S A T$ precedes the determination of WTDIF. Since, however, the higher-order effects are very small, this assumption does not affect the computations in Table 8.
} 


\section{TABLE 9}

Ordinary Least Squares Estimates of Wives' Schooling, Weight Differences, and Job Satisfaction Functions ${ }^{\text {a }}$

\begin{tabular}{|c|c|c|c|}
\hline & $S W I F E$ Function & WTDIF Function & $J S A T$ Function \\
\hline Variable & $\begin{array}{l}\text { Regression } \\
\text { Coefficient }\end{array}$ & $\begin{array}{l}\text { Regression } \\
\text { Coefficient }\end{array}$ & $\begin{array}{l}\text { Regression } \\
\text { Coefficient }\end{array}$ \\
\hline \multirow[t]{2}{*}{$A$} & .018 & .032 & .001 \\
\hline & $(1.21)$ & $(0.24)$ & $(0.23)$ \\
\hline \multirow[t]{2}{*}{$S$} & .302 & -.282 & .014 \\
\hline & $(21.50)$ & $(-2.15)$ & $(2.23)$ \\
\hline \multirow[t]{2}{*}{$S F A T$} & .077 & -.157 & -.0001 \\
\hline & $(7.51)$ & $(-1.73)$ & $(-0.02)$ \\
\hline \multirow[t]{2}{*}{$S M O T$} & .055 & -.164 & .006 \\
\hline & $(5.20)$ & $(-1,78)$ & $(1.37)$ \\
\hline \multirow[t]{2}{*}{$V$} & -.002 & -.172 & -.006 \\
\hline & $(-0.06)$ & $(-0.80)$ & $(-0.56)$ \\
\hline \multirow[t]{2}{*}{ In $H H S$} & .173 & 1.643 & .177 \\
\hline & $(1.39)$ & $(1.51)$ & $(3.50)$ \\
\hline \multirow[t]{2}{*}{$\ln W$} & .046 & -.279 & .240 \\
\hline & $(0.67)$ & $(-0.46)$ & $(8.54)$ \\
\hline \multirow[t]{2}{*}{ OTINC } & .015 & .014 & -.003 \\
\hline & $(2.80)$ & $(0.29)$ & $(-1.52)$ \\
\hline \multirow[t]{2}{*}{$S W I F E$} & . & -.114 & .006 \\
\hline & & $(-0.77)$ & $(0.85)$ \\
\hline$R^{2}$ & .189 & .008 & .036 \\
\hline
\end{tabular}

a $t$ ratios in parentheses.

estimates of the first three equations in the recursive system. ${ }^{58}$ These equations may be viewed as demand curves for three inputs into the production of health although wives' schooling, weight difference, and job satisfaction also enter the production functions of other household commodities.

According to Table 9, schooling is the only predictor variable that has a significant effect on all three inputs. For example, while the hourly wage rate is the best predictor of job satisfaction, it is not related to wives' schooling or weight difference. These results reveal

${ }^{38}$ Since the sequence in which job satisfaction and weight difference are determined is somewhat arbitrary, job satisfaction is omitted from the weight difference equation. 
The Correlation between Health and Schooling 187

TABLE 10

Ordinary Least Squares Estimate of Dichotomous

Excellent Health Function ${ }^{\text {a }}$

\begin{tabular}{|c|c|c|c|}
\hline Variable & $\begin{array}{l}\text { Regression } \\
\text { Coefficient }\end{array}$ & Variable & $\begin{array}{l}\text { Regression } \\
\text { Coefficient }\end{array}$ \\
\hline$A$ & $\begin{array}{l}-.009 \\
(-2.53)\end{array}$ & $S W I F E$ & $\begin{array}{r}.011 \\
(2.75)\end{array}$ \\
\hline$S$ & $\begin{array}{r}.010 \\
(2.82)\end{array}$ & $J S A T$ & $\begin{array}{r}.053 \\
(5.18)\end{array}$ \\
\hline$S F A T$ & $\begin{array}{r}.001 \\
(0.39)\end{array}$ & WTDIF & $\begin{array}{l}-.002 \\
(-3.97)\end{array}$ \\
\hline$S M O T$ & $\begin{array}{r}.005 \\
(1.76)\end{array}$ & $\ln W$ & $\begin{array}{r}.101 \\
(5.88)\end{array}$ \\
\hline$V$ & $\begin{array}{r}.022 \\
(3.71)\end{array}$ & OTINC & $\begin{array}{c}-.001 \\
(-0.55)\end{array}$ \\
\hline $\ln H H S$ & $\begin{array}{c}.314 \\
(10.21)\end{array}$ & $R^{2}$ & .089 \\
\hline
\end{tabular}

${ }^{a} t$ ratios in parentheses.

the important role of schooling in many aspects of consumer behavior. Clearly, a more careful examination of the process by which schooling influences behavior and the mechanisms by which it operates should be given high priority on an agenda for future research. ${ }^{59}$

\section{Estimates of Excellent Health Functions}

To examine the sensitivity of the results in part $A$ of this section to the manner in which I scaled health status, I created a dichotomous variable $(E X C E L L)$ that is equal to one if a man is in excellent health and is equal to zero otherwise. This variable has a mean of .5951, which indicates that approximately 60 per cent of the sample are in excellent health. Table 10 contains an ordinary least squares regression of the dichotomous excellent health variable on the same set of independent variables that enter equation 6 in Table 5. For given values of the independent variables, the predicted value of the dependent variable can be interpreted as the conditional probability that a man is in excellent health. Similarly, the regression coefficient of a

\footnotetext{
${ }^{59}$ I have probably "contaminated" the NBER-Thorndike sample for research along
} these lines, but other data sets can be utilized. 
given independent variable shows the change in the conditional probability of being in excellent health for a one-unit (1 per cent in the case of $\ln H H S$ or $\ln W$ ) change in this variable.

The magnitudes of the regression coefficients in Table 10 should and do differ from the magnitudes of the corresponding coefficients in Table 5. The signs of these two sets of regression coefficients are, however, identical, and the same patterns of statistical significance emerge from the two equations. These findings should strengthen confidence in the results obtained with $\ln H 69$ as the dependent variable in the current health function. This variable, like the theoretical index of health capital, is free of units. Moreover, there is some theoretical justification for the scales used to create it, and for the magnitudes of its regression coefficients.

It is well known that certain statistical problems arise when the dependent variable in an ordinary least squares regression is dichotomous. ${ }^{60}$ In particular, the regression in Table 10 does not take account of the restriction that the conditional probability of being in excellent health should lie between zero and one. To take account of this restriction, I have estimated a dichotomous logit excellent health function by the method of maximum likelihood. This technique assumes that the probability that the $i$ th individual is in excellent health $\left(p_{i}\right)$ is given by the logistic function

$$
p_{i}=1 /\left(1+e^{-a} e^{-b x_{i}}\right)
$$

where $x_{i}$ is an independent variable (or a vector of variables) and $a$ and $b$ are parameters to be estimated. With the logistic function, the predicted value of $p_{i}$ must fall between zero and one. By solving for the logarithm of the odds of being in excellent health, one transforms the logistic function into a linear equation:

$$
\ln \left[p_{i} /\left(1-p_{i}\right)\right]=a+b x_{i}
$$

which is called the logit function. ${ }^{61}$ The logit coefficient $b$ shows the percentage change in the odds for a one-unit change in $x_{i}$. The marginal effect of $x_{i}$ on $p_{i}$ (the change in $p_{i}$ due to a one-unit change in $x_{i}$ ) is given by

$$
\left(\partial p_{i} / \partial x_{i}\right)=b p_{i}\left(1-p_{i}\right)
$$

\footnotetext{
${ }^{60}$ For an extensive discussion of these problems and a complete description of alternative estimation techniques, see Nerlove and Press (1973).

${ }^{61}$ See Berkson $(1944,1955)$ for detailed analyses of the properties of the logit function.
} 
TABLE 11

Maximum Likelihood Estimate of Dichotomous

Logit Excellent Health Function ${ }^{\text {a }}$

\begin{tabular}{|c|c|c|c|c|c|}
\hline Variable & $\begin{array}{c}\text { Logit } \\
\text { Coefficient }\end{array}$ & $\begin{array}{c}\text { Marginal } \\
\text { Effect }\end{array}$ & Variable & $\begin{array}{c}\text { Logit } \\
\text { Coefficient }\end{array}$ & $\begin{array}{c}\text { Marginal } \\
\text { Effect }\end{array}$ \\
\hline$A$ & $\begin{array}{c}-.041 \\
(-2.49)\end{array}$ & -.010 & $S W I F E$ & $\begin{array}{r}.053 \\
(2.76)\end{array}$ & .013 \\
\hline$S$ & $\begin{array}{r}.046 \\
(2.74)\end{array}$ & .011 & $J S A T$ & $\begin{array}{r}.237 \\
(5.12)\end{array}$ & .057 \\
\hline$S F A T$ & $\begin{array}{r}.004 \\
(0.36)\end{array}$ & .001 & $W T D I F$ & $\begin{array}{l}-.008 \\
(-3.91)\end{array}$ & -.002 \\
\hline$S M O T$ & $\begin{array}{r}.020 \\
(1.73)\end{array}$ & .005 & $\ln W$ & $\begin{array}{l}.466 \\
(5.79)\end{array}$ & .112 \\
\hline$V$ & $\begin{array}{r}.101 \\
(3.66)\end{array}$ & .024 & OTINC & $\begin{array}{c}-.003 \\
(-0.54)\end{array}$ & -.001 \\
\hline $\ln H H S$ & $\begin{array}{l}1.427 \\
(9.56)\end{array}$ & .344 & & & \\
\hline
\end{tabular}

${ }^{a}$ Asymptotic $t$ ratios in parentheses.

Table 11 contains an estimate of a dichotomous logit excellent health function. ${ }^{62}$ The marginal effects in the table are computed at the mean value of $p$ for the sample of .5951 . A comparison of the results in Tables 10 and 11 reveals that all variables have the same signs in the ordinary least squares excellent health function as they have in the logit function. Tests of statistical significance yield identical conclusions when applied to either function. Moreover, the marginal effects in Table 11 are approximately equal to the corresponding regression coefficients in Table 10. It should be noted that problems similar to

${ }^{62}$ To see how this function is obtained, consider a sample in which, for simplicity, the first $m$ men are in excellent health and the next $n-m$ are not. The natural logarithm of the likelihood function associated with this sample is

$$
\ln L=\sum_{i=1}^{m} \ln p_{i}+\sum_{i=m+1}^{n} \ln \left(1-p_{i}\right)
$$

Assuming that the relationship between $p_{i}$ and $x_{i}$ is given by the logistic function and maximizing $\ln L$ with respect to $a$ and $b$, one obtains the estimates in Table 11. The ratios of logit coefficients to their standard errors do not have Student's $t$ distribution. These ratios do, however, approach the normal distribution as the sample size becomes large. Therefore, the $t$ test is an asymptotic one, which can be applied to the logit function I estimate, since there are over 3,500 observations. 
those that are encountered when a dependent variable is dichotomous are also encountered when it is polytomous. ${ }^{63}$ Since my health capital series has only four possible values, it generates a polytomous variable. Yet an extrapolation of the comparison between ordinary least squares and logit excellent health functions would suggest that one would gain little by using estimation techniques other than ordinary least squares simply because $\ln H 69$ is polytomous.

\section{ESTIMATES OF A SIMULTANEOUS-EQUATIONS}

\section{HEALTH-WAGE MODEL}

\section{A. Introduction}

In previous sections of this paper, I assumed that the current stock of health is not a determinant of the current stock of human capital. I now relax this assumption and examine the possibility that health capital, as one component of human capital, raises market productivity and the hourly wage rate. Empirically, I estimate a simultaneous-equations model by the method of two-stage least squares, in which current health and the hourly wage rate are endogenous variables.

There are both theoretical and empirical reasons for proceeding along these lines. At a theoretical level, the distinction that $I$ have drawn between adults' health capital as a determinant of their total available time and their human capital as a determinant of their productivity may be too extreme. If, as I have postulated, students' health influences their productivity in school, then should not adults' health influence their productivity in the labor market? Moreover, Malkiel and Malkiel (1973) hypothesize that employers may lower the wage offered to employees who work fewer hours in a year due to illness and other reasons. Finally, Mincer $(1970,1974)$ stresses that investment in on-the-job training, measured by the total amount of time spent in such activity, plays a major role in the wage function. This variable is imperfectly measured in most data sets. The best available proxy is years of experience in the labor market, which itself is subject to measurement error. To the extent that poor health reduces the amount of time spent in the labor market, current health may affect the current wage via its impact on past investment in on-the-job training.

At an empirical level, studies by Boskin (1971); Hall (1973); and Luft (1972) suggest that health, treated as an exogenous variable, does have a positive effect on the wage rate. Benham and I (Grossman and Benham 1974) also find a positive impact of health on the wage

${ }^{63}$ See Nerlove and Press (1973). 
when both variables are treated as endogenous in the NORC sample. Therefore, part of the positive relationship between these two variables in the regressions in Section III may reflect causality from health to market productivity. The health-wage model that $I$ estimate in this section may be viewed as an extension of the Grossman-Benham model, although the measure of health and the set of exogenous variables are somewhat different.

I want to emphasize that there are costs to be paid as well as benefits to be gained as a result of simultaneous-equations estimation. In particular, I have found in previous work that when this method is applied to microdata, results tend to be fairly sensitive to the manner in which equations are "identified." Although it might be clear in theory that a certain subset of exogenous variables should be included in one equation and excluded from another, key members of this subset might not be available in the data. Another problem in applying two-stage least squares, for example, to microdata is that coefficients of determination in the first stage rarely exceed 30 or 40 per cent. Therefore, in selecting between two-stage least squares and ordinary least squares estimates, one is forced to make a tradeoff between consistency and efficiency. ${ }^{64}$ Given these factors, and given the far from ideal way in which health is measured in the NBER-Thorndike sample, I view the model that is formulated and fitted in this section as an illustration of the kind of model that could be fitted with more refined data. The parameter estimates that I present are by no means definitive. For the same reasons, I also view the simultaneous-equations model as a complement to, rather than a substitute for, the ordinary least squares model.

\section{B. Specification of Structural Equations}

The structural equations for health and the hourly wage rate are as follows:

$$
\begin{aligned}
\ln H 69=b_{1} A & +b_{2} S+b_{3} V+b_{4} \ln H H S+b_{5} S W I F E \\
& +b_{6} J S A T+b_{7} W T D I F+b_{8} \ln W^{*}+b_{9} O T I N C
\end{aligned}
$$

$\ln W=a_{1} \ln H 69^{*}+a_{2} S+a_{3} E X P+a_{4} G E N+a_{5} S O U T H+a_{6} C S 1$

$$
+a_{7} C S 2+a_{8} C S 3+a_{9} C S 4+a_{10} C S 5
$$

An asterisk next to a variable in equation 17 or 18 means it is endogenous. Variables in the wage function that were not included in the analy-

\footnotetext{
ot Finis Welch has stressed this point to me on a number of occasions.
} 
TABLE 12

Definition of Supplementary Variables

\begin{tabular}{ll}
\hline \hline Variable & \\
\hline EXP & Years of experience in the labor force \\
SOUTH & Reside in South $=1$ \\
$C S 1^{\mathrm{b}}$ & Reside in a small town $(2,500-10,000$ people $)=1$ \\
$C S 2^{\mathrm{b}}$ & Reside in a town $(10,000-50,000$ people $)=1$ \\
$C S 3^{\mathrm{b}}$ & Reside in a moderate-sized city $(50,000-250,000$ people $)=1$ \\
$C S 4^{\mathrm{b}}$ & Reside in a large city (250,000-1 million people) $=1$ \\
$C S 5^{\mathrm{b}}$ & Reside in a major metropolitan area (over 1 million people) $=1$
\end{tabular}

a See text for a more complete definition.

- Omitted class is reside in a rural area (under 2,500 people).

sis in Section III are defined in Table 12. The specification of the health function was fully discussed in previous sections. Here, I would simply point out that I omit mothers' schooling and fathers' schooling from this function. That is, I assume that any gross effects of these two variables on health operate solely via their effects on own schooling or past health. ${ }^{65}$

The wage function is based on work on wage determination by Becker and Chiswick (1966); Mincer (1970, 1974); and Lillard (1973). These authors emphasize that wage rates should be positively related to correlates of the stock of human capital, such as years of formal schooling completed, years of experience in the labor force, general intelligence, and current health. Obviously, years of formal schooling completed is a partial measure of the quantity of investment in knowledge via schooling, while years of experience in the labor market, defined as the number of years since a man was last in school, is a partial measure of the quantity of investment in on-the-job training. General intelligence and health may influence the quantities of both types of investment. Note that, if the dependent variable in equation 18 were annual earnings or weekly earnings, a positive health effect might simply mean that health raises weeks worked per year or hours worked per week but has no effect on market productivity. Since, however, the dependent variable in the equation is the natural logarithm of the hourly wage rate, one cannot interpret a positive health coefficient along these lines. ${ }^{6}$

${ }_{65}^{65}$ Two-stage least squares estimates obtained with these two variables in the health function (not shown) are almost identical to those presented in part $C$ of this section.

${ }^{66}$ I exclude the square of years of experience from equation 18 , because the dependent variable is the hourly wage rate. Although theory and previous empirical research sug- 
I add dummy variables for region and city size to the basic set of human capital variables in the wage function. I assume that these variables mainly capture shifts in the demand curve for labor around a fairly stable supply curve among labor markets in the United States. Undoubtedly, part of the variation in wages by region and city size is due to differences in the cost of living. Since the health function should relate health to the wage rate, with the prices of medical care and other market goods used to produce health held constant, region and city size might also be entered in the health function. However, in that function, they might reflect other factors as well, such as variation in the availability of medical care, not associated with the price of care and climate. Some of these factors might offset differences in the cost of living. Moreover, the health components of an aggregate price index might not vary in the same manner as the index itself among regions and cities of various sizes. Since I have not emphasized region and city-size health differentials, and since predictions concerning these differentials are ambiguous, I do not include these variables in the health function. To the extent that the money wage rate is positively correlated with the prices of health inputs, the estimated wage elasticity of health would be biased downward. ${ }^{67}$

\section{Results}

Table 13 contains two-stage least squares estimates of health functions, and Table 14 contains two-stage least squares estimates of wage functions. ${ }^{68}$ The results in the latter table reveal that the endogenous current health variable has a positive and very significant effect on the hourly wage rate. As shown by its regression coefficient in equation 1 ,

gest that experience-earnings profiles or experience-weekly-wage profiles should be concave to the origin (Becker 1967; Ben-Porath 1967; Mincer 1970, 1974; Lillard 1973), I find no empirical evidence that experience-hourly-wage profiles are concave. This may be due in part to the limited age range in the NBER-Thorndike sample.

${ }^{67}$ If the health demand curve given by equation $9^{\prime \prime}$ is differentiated with respect to the wage rate, and if the composite price of medical care and other inputs $(P)$ varies with the wage, then

$(d \ln H / d \ln W)=\alpha \in[1-(d \ln P / d \ln W)]$

${ }^{68}$ When two-stage least squares estimation is employed, the ratios of regression coefficients to their standard errors do not have Student's $t$ distribution but do have an asymptotic normal distribution. Therefore, the $t$ test is an asymptotic one. The unadjusted coefficients of multiple determination $\left(R^{2}\right)$ in Tables 13 and 14 should be interpreted with caution. I forced the $R^{2}$ to fall between zero and one, for example, by using the variance in the logarithm of the predicted wage rather than the variance in the logarithm of the actual wage in computing the ones in Table 13. I used this procedure to get a rough approximation of "explanatory power." Since age, schooling, and experience are almost perfectly collinear, I omitted experience from the first-stage health equation. Similarly, I omitted age from the first-stage wage equation. 
TABLE 13

Two-Stage Squares Estimates of Health Functions ${ }^{\text {a }}$

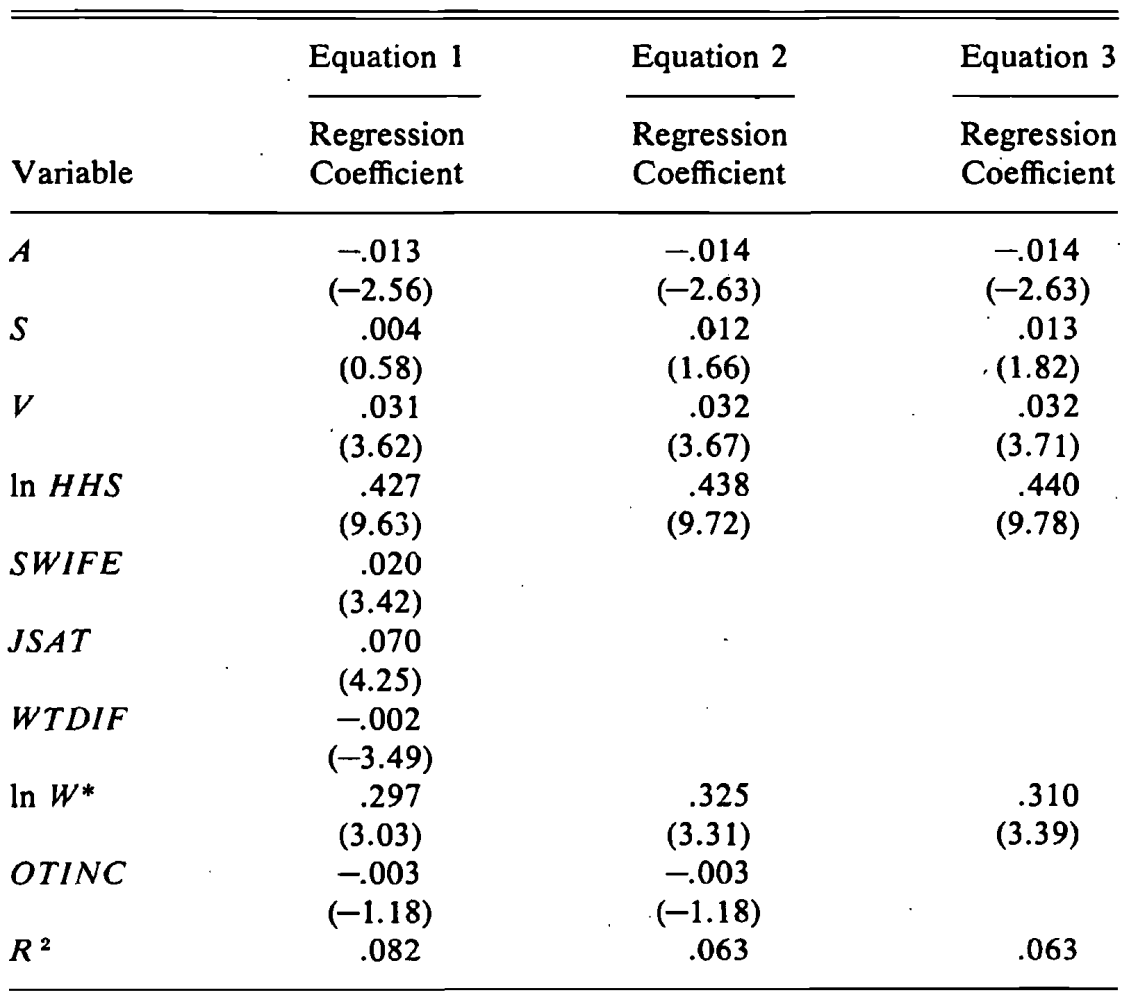

a An asterisk next to a variable means that it is endogenous. Asymptotic $t$ ratios in parentheses. See Tables 3 and 12 for definitions of variables.

a 10 per cent increase in the stock of current health causes the hourly wage rate to rise by approximately 4 per cent. The signs of the regression coefficients of the other variables in the wage equation are consistent with a priori expectations.

In Table 13, I demonstrate that when the wage is treated as an endogenous variable, a striking change occurs in the health function coefficient of this variable. In equation 6 in Table 5 , the wage elasticity of health equals .15. In equation 1 in Table 13, this elasticity equals .30 . This doubling in the wage elasticity occurs despite the presumed upward bias in the ordinary least squares estimate because it reflects causality from health to the wage as well as causality from the wage to 
The Correlation between Health and Schooling 195

TABLE 14

Two-Stage Least Squares Estimates of Wage Functions a

\begin{tabular}{|c|c|c|c|}
\hline \multirow[b]{2}{*}{ Variable } & \multirow{2}{*}{$\begin{array}{l}\text { Equation } 1 \\
\text { Regression } \\
\text { Coefficient }\end{array}$} & \multirow{2}{*}{$\frac{\text { Equation } 2^{b}}{\begin{array}{c}\text { Regression } \\
\text { Coefficient }\end{array}}$} & \multirow{2}{*}{$\begin{array}{l}\text { Equation } 3 \mathrm{c} \\
\text { Regression } \\
\text { Coefficient }\end{array}$} \\
\hline & & & \\
\hline \multirow[t]{2}{*}{$\ln H 69^{*}$} & .403 & .314 & .254 \\
\hline & $(7.83)$ & $(5.23)$ & $(4.31)$ \\
\hline \multirow[t]{2}{*}{$S$} & .043 & .046 & .048 \\
\hline & (9.10) & $(10.15)$ & $(10.80)$ \\
\hline \multirow[t]{2}{*}{$E X P$} & .007 & .007 & .007 \\
\hline & $(4.35)$ & $(4.90)$ & $(4.98)$ \\
\hline \multirow[t]{2}{*}{$G E N$} & .031 & .033 & .034 \\
\hline & $(5.46)$ & (5.98) & $(6.35)$ \\
\hline \multirow[t]{2}{*}{ SOUTH } & -.013 & -.014 & -.015 \\
\hline & $(-0.63)$ & $(-0.73)$ & $(-0.79)$ \\
\hline \multirow[t]{2}{*}{$C S 1$} & .157 & .155 & .154 \\
\hline & $(4.56)$ & $(4.73)$ & $(4.81)$ \\
\hline \multirow[t]{2}{*}{$C S 2$} & .182 & .190 & .195 \\
\hline & $(5.75)$ & $(6.25)$ & (6.58) \\
\hline \multirow[t]{2}{*}{$C S 3$} & .207 & .213 & .217 \\
\hline & (6.24) & $(6.71)$ & $(7.00)$ \\
\hline \multirow[t]{2}{*}{ CS4 } & .224 & .236 & .243 \\
\hline & $(6.23)$ & $(6.80)$ & $(7.18)$ \\
\hline \multirow[t]{2}{*}{ CS5 } & .348 & .358 & .365 \\
\hline & $(9.86)$ & $(10.56)$ & (11.03) \\
\hline$R^{2}$ & .166 & .156 & .153 \\
\hline
\end{tabular}

${ }^{a}$ An asterisk next to a variable means it is endogenous. Asymptotic $t$ ratios in parentheses.

b $S W I F E, J S A T$, and $W T D I F$ excluded from the set of instrumental variables.

c $S W I F E, J S A T, W T D I F$, and $O T I N C$ excluded from the set of instrumental variables.

health. ${ }^{69} \mathrm{~A}$ possible explanation of this finding is that there might be measurement error in the computed hourly wage variable, which would bias the ordinary least squares parameter estimate downward. This

${ }^{69}$ Suppose that the wage elasticity of health $\left(b_{8}\right)$ and the health elasticity of the wage $\left(a_{1}\right)$ are positive. Then the simultaneous-equations system given by equations 17 and 18 would have a stable solution if, and only if, the product of $b_{8}$ and $a_{1}$ were smaller than one. This follows because the reduced-form health parameter of $\ln H H S$, for example, is $b_{4} /\left(1-b_{8} a_{1}\right)$. Since $b_{8}$ equals .30 and $a_{1}$ equals .40 , the stability condition is satisfied at an empirical level. 
bias should be reduced by the use of a set of instrumental variables via the method of two-stage least squares.

In the health-wage model that Benham and I (Grossman and Benham 1974) fit to the NORC sample, the endogenous wage rate has a negative effect on health rather than a positive effect. We argue that this might reflect a greater tendency to select occupations that are hazardous or otherwise detrimental to health as the wage rate rises, with schooling and experience held constant. It should be noted that Benham and $I$ include proxy variables for preventive medical care in our health function. This is one source of the discrepancy between the signs of the wage elasticities in the NORC and NBER-Thorndike samples. Another source is that the NORC health function is estimated for all white men, while the NBER-Thorndike health function is estimated for a high-earnings, high-schooling, and high-ability sample. Variations in wages associated with harmful health characteristics of occupations might be much more important at low levels of earnings and schooling than at high levels.

In general, there are two theoretical reasons for an increase in the wage elasticity of health as the wage rate rises. First, if the elasticity of substitution between own time and market goods in the health production function exceeded one, then the share of market goods in the total cost of producing health $(\alpha)$ would rise with the wage. This would increase the wage parameter $(\alpha \epsilon)$ in the health demand curve. Second, the positive relationship between the wage rate and what I have termed "the inconvenience costs of illness" (Grossman 1972b, p. 69) might become stronger as the wage grows. This relationship arises because the complexity of a particular job and the amount of responsibility it entails certainly are positively correlated with the wage. Thus, when an individual with a high wage becomes ill, tasks that only he can perform accumulate. These increase the intensity of his work load and give him an incentive to avoid illness by demanding more health capital. I suspect that the importance of inconvenience costs in the NBER-Thorndike sample is the major source of the large wage elasticity of health that is observed in this sample. By using a set of instrumental variables for the wage rate, I probably create a variable that more accurately reflects these costs than the measured wage.

With two exceptions, the health coefficients of variables other than the wage are not altered much when the wage is treated as endogenous. The two exceptions are that the coefficient of nonearnings income increases in absolute value and the coefficient of own schooling falls dramatically (compare equation 1 in Table 13 to equation 6 in Table 
$5)$. The pure income elasticity of health rises in absolute value from -.01 to -.06 at an income of $\$ 20,000$ when the health function is estimated by two-stage least squares rather than by ordinary least squares. Although the pure income elasticity is still not statistically significant, its sign suggests that, at high income levels, the consumption of detrimental health inputs grows at least as rapidly as the consumption of beneficial inputs as income grows. In a statistical sense, the reduction in the coefficient of own schooling is due to multicollinearity between schooling and the predicted wage rate. These two variables are much more highly correlated than schooling and the actual wage rate $(r=$ .642 versus $r=.289$ ). In a literal sense, according to equation 1 in Table 13, schooling has no direct effect on health, with the wage rate and other variables held constant.

Even if the literal interpretation of the schooling coefficient in equation 1 is correct, this does not mean that schooling has no impact on health independent of its impact on the wage rate. In part B of Section II, I showed that schooling influences health in part because of its effects on wives' schooling, weight difference, and job satisfaction. Equation 2 in Table 13 allows the schooling coefficient to reflect these channels by omitting wives' schooling, job satisfaction, and weight difference from the model. The omission of these three variables causes the schooling coefficient to triple in magnitude and to achieve statistical significance at the .05 level of confidence on a one-tail test. Greenberg (1972) and Smith (1973) argue that it is not entirely appropriate to treat nonearnings income as an exogenous variable in the context of a model of life-cycle decision making. Therefore, equation 3 excludes this variable as well as the three excluded in equation 2 . This results in a slightly larger and a slightly more significant schooling coefficient. $^{7 n}$

${ }^{70}$ Clearly, within the context of a life-cycle model, wives' schooling, job satisfaction, weight difference, and nonearnings income are endogenous variables. If these variables are determined prior to the determination of current health and the current wage, it would be appropriate to use them as instruments in two-stage least squares. If, however, they are determined simultaneously with current health and the current wage, they should not be used as instruments. I have not tried to estimate equation 1 in Table 13 by specifying separate equations for $S W I F E, J S A T, W T D I F$, and $O T I N C$. I have estimated equation 1 with these variables entered in the second-stage health function but excluded from the first-stage. Coefficients obtained in this manner are almost identical to those shown in equation 1.

Equation 2 in Table 14 gives the wage function that is obtained when SWIFE, JSAT, and $W T D I F$ are excluded from the health function, and equation 3 gives the wage function that is obtained when these three variables and OTINC are excluded. The main impact of these exclusions is to reduce the elasticity of the wage with respect to health from approximately .4 to approximately .3. The smaller elasticity is still significant at all conventional levels of confidence. 
TABLE 15

Estimates of Direct, Indirect, and Total Effects of Schooling on Health and the Wage Rate

\begin{tabular}{lcc}
\hline \hline & Health Effects & Wage Effects \\
\hline Direct effect & .014 & .052 \\
Indirect effect & .016 & .003 \\
Total effect (reduced-form parameter) & .030 & .055 \\
\hline
\end{tabular}

Due to the importance of schooling as a policy variable from the point of view of both the individual and society, it is useful to examine the reduced-form health and schooling parameters of this variable. In Table 15, I show estimates of these parameters based on a specification of the health function that omits wives' schooling, job satisfaction, weight difference, and nonearnings income. I also decompose each parameter into a direct component and an indirect component. ${ }^{71}$ The reduced-form health parameter of schooling indicates that a one-year increase in this variable raises health by 3.0 per cent. The indirect component, which is present because schooling raises the wage rate and the wage rate raises health, is slightly larger than the direct component. The reduced-form wage parameter of schooling suggests a rate of return to investment in schooling via an expansion in market productivity of 5.5 per cent. A small percentage of this increase (approximately 5.45 per cent) can be attributed to the increase in health caused by an increase in schooling.

In a sense, the direct component of the reduced-form health parameter is itself an indirect component, because it measures the effects of schooling on health that operate via wives' schooling, job satisfaction, and weight difference. Regardless of the manner in which the direct component is interpreted, its magnitude suggests that schooling influences health by channels other than the wage rate. Given the high degree of multicollinearity between schooling and the predicted wage, this is an impressive finding. Future research is necessary in order to ascertain whether the direct nonmarket productivity component of the

"Given the simultaneous-equations system specified by equations 17 and 18 , the reduced-form health parameter of schooling equals $\left(b_{2}+a_{2} b_{8}\right) /\left(1-b_{8} a_{1}\right)$. The term $b_{2} /$ $\left(1-b_{8} a_{1}\right)$ gives the direct component, and the term $a_{2} b_{\mathrm{B}} /\left(1-b_{\mathrm{x}} a_{1}\right)$ gives the indirect component. Similarly, the reduced-form wage parameter of schooling equals $\left(a_{2}+b_{2} a_{1}\right) /$ $\left(1-b_{8} a_{1}\right)$, where $a_{9} /\left(1-b_{x} a_{1}\right)$ is the direct component and $b_{2} a_{1} /\left(1-b_{8} a_{1}\right)$ is the indirect component. 
schooling coefficient in the health function is really as small as the simultaneous-equations model indicates, and whether the indirect nonmarket component is as large.

\section{MORTALITY EXPERIENCE OF THE THORNDIKE SAMPLE BETWEEN 1955 AND 1969}

\section{A. Nature of the Analysis}

Death is the most objective, although the most extreme, measure of ill health. Therefore, in this section I examine the mortality experience of the Thorndike sample between the year of the initial survey by Thorndike and Hagen (1955) and the year of the first resurvey by the NBER (1969). In particular, I want to see whether relationships that are observed when health is measured by self-rated health status are also observed when health is measured by mortality or survival.

Of the 9,700 men in the original Thorndike sample, 275 had died by $1969 .^{72}$ This gives a mortality rate of 2.84 per cent over a period that extends roughly from 1956 through 1968 . In 1955, the mean age of the sample was thirty-three years, and the age-specific death rate in the United States of white males ages thirty-five to forty-four was 0.34 per cent (National Center for Health Statistics 1961). Since this agespecific death rate was practically constant between 1956 and 1968 , 4.32 per cent of the Thorndike sample would have died by 1968 if the sample had the same mortality experience as the population at large. ${ }^{73}$ Thus, the survival rate in a sample drawn from the upper tails of the schooling, earnings, and scholastic-ability distributions exceeds the survival rate in the general population. This complements my finding that the levels of self-rated health status and healthy time in the NBERThorndike sample exceed the levels of these health indexes in the NORC sample.

To examine the partial effects of various factors on survival in the Thorndike sample, I have estimated a dichotomous logit survival function by the method of maximum likelihood. ${ }^{74}$ If $p_{i}$ is the probability that the $i$ th individual survives, then this function is given by

\footnotetext{
${ }^{12}$ Although the response rate to the 1969 questionnaire was only slightly higher than 50 per cent, it is known with certainty that exactly 275 men died. This information was supplied by the Veterans Administration.

${ }^{73}$ If the age-specific death rate of a cohort $(d)$ is constant over time, then the fraction who die in a $t$-year period would equal $1-(1-d)^{t}$.

${ }^{74} \mathrm{I}$. have also estimated dichotomous survival functions by ordinary least squares. The results (not shown) are almost identical to those obtained with the logit functions in part B of this section.
} 
$\ln \left[p_{i} /\left(1-p_{i}\right)\right]=b_{1} S+b_{2} V+b_{3} P+b_{4} M E C H+b_{5} G E N$

$$
+b_{6} N U M+b_{7} J S A T 55+b_{8} \ln S A L 55
$$

where $S$ is years of formal schooling completed in 1955, JSAT55 is an index of job satisfaction in 1955, $\ln S A L 55$ is the natural logarithm of full-time salary in 1955, and the other variables are defined in Section II. The logit function contains only eight independent variables, because no information is available on people who died between 1955 and 1969 other than that collected by Thorndike and Hagen in 1955. Fulltime salary rather than the hourly wage rate measures the value of time, because there are no data on hours worked per week in 1955. Job satisfaction in 1955 is simply the answer to the question: How well do you like the type of work you are doing now? The four possible numerical responses constitute a scale ranging from four (the highest) to one (the lowest).

I could have used all 9,700 men in the original sample as a base for estimating the logit function, but, for two reasons, I have limited observations on survivors to men who responded to the 1969 NBER questionnaire. First, a significant fraction of the sample completed their formal schooling after $1955 . .^{75}$ Therefore, a positive relationship between schooling in 1955 and survival might reflect the incentive of persons with a longer life expectancy and a higher level of general health to invest more in schooling. By using the 1969 survey as a base, I can restrict the survivors to men who had completed their formal schooling by 1955 .

Second, Thorndike and Hagen did not obtain age as a variable in 1955. Since age and schooling are negatively correlated and age and survival are presumably negatively correlated, the effect of schooling on survival is biased upward by the omission of age from the survival function. By selecting survivors who had completed their formal schooling by 1955 , I select a set whose mean age is somewhat greater than the mean age of all survivors. At the same time, I reduce the size of the correlation between age and schooling. This procedure mitigates, although it does not entirely eliminate, the bias caused by omitting age from the survival function. ${ }^{76}$

${ }^{75}$ Of the 5,085 respondents to the 1969 questionnaire, 11 per cent completed schooling after 1955 .

${ }^{76} \mathrm{My}$ procedure assumes that men who completed schooling by 1955 and responded to the 1969 questionnaire have the same characteristics as all men who survived and completed schooling by 1955 . Taubman and Wales (1974) indicate that men who responded to the 1969 questionnaire reported slightly higher schooling levels in 1955 than the entire 1955 sample. But their comparison is not restricted to men who finished schooling by 1955 . 
The Correlation between Health and Schooling 201 TABLE 16

Characteristics of Samples in Survival Analysis

\begin{tabular}{llcc}
\hline \hline \multicolumn{1}{c}{ Sample } & Size & Deaths & $\begin{array}{c}\text { Adjusted } \\
\text { Mortality Rate } \\
\text { (Per Cent) }\end{array}$ \\
\hline $\begin{array}{l}\text { Positive salary in 1955 } \\
\begin{array}{l}\text { Salary exceeds one-half } \\
\text { the median salary }\end{array}\end{array}$ & 4,386 & 248 & 2.83 \\
$\begin{array}{l}\text { Salary exceeds the } \\
\text { median salary }\end{array}$ & 4,277 & 238 & 2.78 \\
\hline
\end{tabular}

Note that men with zero or unknown full-time salaries in 1955 are excluded from the analysis. Therefore, persons who died shortly after 1955 and were not able to work at all in that year are eliminated from the survival function. To further reduce the magnitude of a possible relationship from survival to full-time salary, I estimate survival functions for men whose 1955 full-time salary exceeds one-half the median full-time salary of $\$ 6,000$ and for men whose salary exceeds the median salary. This procedure alleviates problems that arise because I do not know whether decedents completed their formal schooling by 1955 . It is unlikely that a decedent whose salary exceeded the median salary had not finished his schooling.

The sample size, number of deaths, and "adjusted mortality rate" in each of the three logit functions that I fit are shown in Table 16. Since the response rate to the 1969 questionnaire was approximately 50 per cent, the decedents in each sample represent 100 per cent of all decedents, but the survivors represent 50 per cent of all survivors. Therefore, in computing the adjusted mortality rate, I give double weight to survivors. In calculating logistic functions, I do not give double weight to survivors, but I do estimate marginal effects at the adjusted mean probability of survival (one minus the adjusted death rate). ${ }^{77}$

\section{B. Results}

Table 17 contains maximum likelihood estimates of dichotomous logit survival functions. The three equations in the table reveal that

\footnotetext{
${ }^{77}$ In regression analysis, weighting is employed to produce efficient estimates rather than to produce consistent estimates. Consequently, it is by no means obvious that logistics survival functions should be weighted.
} 
TABLE 17

Maximum Likelihood Estimates of Dichotomous

Logit Survival Functions ${ }^{\text {a }}$

\begin{tabular}{|c|c|c|c|c|c|c|}
\hline \multirow[b]{2}{*}{ Variable } & \multicolumn{2}{|c|}{ Equation $1^{b}$} & \multicolumn{2}{|c|}{ Equation $2^{c}$} & \multicolumn{2}{|c|}{ Equation $3^{\text {d }}$} \\
\hline & $\begin{array}{c}\text { Logit } \\
\text { Coeffi- } \\
\text { cient }\end{array}$ & $\begin{array}{c}\text { Marginal } \\
\text { Effect }\end{array}$ & $\begin{array}{c}\text { Logit } \\
\text { Coeffi- } \\
\text { cient }\end{array}$ & $\begin{array}{c}\text { Marginal } \\
\text { Effect }\end{array}$ & $\begin{array}{c}\text { Logit } \\
\text { Coeffi- } \\
\text { cient }\end{array}$ & $\begin{array}{c}\text { Marginal } \\
\text { Effect }\end{array}$ \\
\hline$S$ & $\begin{array}{r}.135 \\
(4.06)\end{array}$ & .004 & $\begin{array}{r}.142 \\
(4.15)\end{array}$ & .004 & $\begin{array}{r}.147 \\
(3.04)\end{array}$ & .004 \\
\hline$V$ & $\begin{array}{r}.037 \\
(0.68)\end{array}$ & .001 & $\begin{array}{r}.037 \\
(0.67)\end{array}$ & .001 & $\begin{array}{r}.058 \\
(0.71)\end{array}$ & .002 \\
\hline$P$ & $\begin{array}{c}-.038 \\
(-0.67)\end{array}$ & -.001 & $\begin{array}{c}-.034 \\
(-0.59)\end{array}$ & -.001 & $\begin{array}{l}-.085 \\
(-0.97)\end{array}$ & -.002 \\
\hline$M E C H$ & $\begin{array}{r}.013 \\
(0.22)\end{array}$ & .0004 & $\begin{array}{r}.015 \\
(0.25)\end{array}$ & .0004 & $\begin{array}{r}.012 \\
(0.13)\end{array}$ & .0003 \\
\hline$G E N$ & $\begin{array}{r}.056 \\
(1.05)\end{array}$ & .002 & $\begin{array}{r}.070 \\
(1.28)\end{array}$ & .002 & $\begin{array}{r}.032 \\
(0.42)\end{array}$ & .001 \\
\hline$N U M$ & $\begin{array}{l}-.013 \\
(-0.24)\end{array}$ & -.0004 & $\begin{array}{c}-.009 \\
(-0.17)\end{array}$ & -.0003 & $\begin{array}{r}.014 \\
(0.17)\end{array}$ & .0004 \\
\hline JSAT55 & $\begin{array}{r}.084 \\
(0.84)\end{array}$ & .002 & $\begin{array}{l}.116 \\
(1.14)\end{array}$ & .003 & $\begin{array}{r}.027 \\
(0.17)\end{array}$ & .001 \\
\hline In $S A L 55$ & $\begin{array}{r}.037 \\
(0.21)\end{array}$ & .001 & $\begin{array}{c}-.087 \\
(-0.46)\end{array}$ & -.002 & $\begin{array}{r}.129 \\
(0.39)\end{array}$ & .003 \\
\hline
\end{tabular}

a Asymptotic $t$ ratios in parentheses.

- Includes all men who completed schooling by 1955 and who had a positive salary in that year. Sample size is 4,386 .

' Includes men whose salary exceeded one-half the median salary. Sample size is 4,277 .

d Includes men whose salary exceeded the median salary. Sample size is 2,013.

schooling has a positive and statistically significant effect on the probability of survival. Indeed, schooling is the only variable whose logit coefficient differs from zero in a statistical sense. The schooling effect is independent of the level of median salary in 1955 and suggests that in the vicinity of the adjusted death rate a one-year increase in schooling lowers the probability of death by .4 percentage points. The important role of schooling in the survival function is a further justification for the emphasis that I have given to this variable as a determinant of health throughout this paper. 
The Correlation between Health and Schooling 203

Although none of the other variables has a statistically significant effect on survival, the signs of job satisfaction and visual perception are consistent with the signs of these variables in the self-rated health status functions. When the lower tail of the salary distribution is included in the analysis, general intelligence is a better predictor of survival than visual perception. This is not, however, the case when the sample is limited to the upper tail of the salary distribution. In general, the estimated schooling parameter and the estimated parameter of a given test score are not sensitive to the other test scores that are included in the survival function.

Two difficulties with the mortality analysis are that the men in the Thorndike sample were only in their thirties in 1955, and that relatively few variables are available for that year. The sample has now reached a point in the life cycle at which death rates in future years should be much higher than in the past. Consequently, one promising area for future research would be to trace the mortality experience of the sample for the next five or ten years. Mortality could then be related to a wide variety of factors that can be measured with the large set of variables that was collected by the NBER in 1969 and 1971 .

\section{SUMMARY AND CONCLUSION}

In this paper, I have used the household production function approach to consumer behavior to develop recursive and simultaneous models of decision making that can be used to formulate and estimate health-schooling relationships. In the theoretical section, I have shown how a recursive system whose principal equations are demand curves for children's health, schooling, and adults' health generates causal relationships from schooling to health and from health to schooling. In addition, this system generates relationships from third variables to both health and schooling. In the main empirical section, I have estimated a recursive health-schooling model by ordinary least squares, using data contained in the NBER-Thorndike sample. In this model, I have measured health capital by self-rated health status. In other empirical sections, I have conducted "sensitivity analyses" that show how the ordinary least squares results are affected (1) when the health equation is specified as a dichotomous logit function and estimated by the method of maximum likelihood, and (2) when the health function is fitted in the context of a simultaneous-equations health-wage model. Finally, I have examined the mortality experience of the Thorndike sample between 1955 and 1969. 
The major empirical results of the recursive health-schooling model can be summarized as follows. With past health and third variables held constant, schooling has a positive and statistically significant effect on current health. This is evidence in favor of a causal relationship that runs from schooling to current health. The estimated bias in schooling coefficients is larger when current variables are omitted from the health function than when past variables are omitted. Current variables include the hourly wage rate, wives' schooling, weight difference, and job satisfaction; while past variables include past health, parents' schooling, and visual perception. Past health has an extremely significant positive effect on current health and also has a positive and significant effect on years of formal schooling completed. Yet the parameter estimate of schooling in the current health function is not greatly altered by the inclusion of past health. Current health is positively related to physical ability, measured by visual perception, but it is not related to mental ability, measured by general intelligence. A decomposition analysis of the effect of schooling on health, with the wage rate held constant, reveals that a substantial fraction of this effect operates via the impact of schooling on wives' schooling, job satisfaction, and weight difference. Indeed, these three channels of influence account for nearly 40 per cent of the total nonmarket productivity effect of schooling on health.

The sensitivity analysis reveals that the qualitative results of the recursive model are not altered when the health equation is specified as a dichotomous logit function and estimated by the technique of maximum likelihood. In the context of the simultaneous-equations health-wage model, schooling has a somewhat smaller impact on health than it does in the pure recursive system. In fact, the simultaneousequations model shows that, with the wage rate held constant, the entire effect of schooling on health operates via the channels of wives' schooling, job satisfaction, and weight difference. This model also shows that health is an important determinant of market productivity and the hourly wage rate. The mortality experience of the Thorndike sample between 1955 and 1969 confirms the important role of schooling in the health function.

I view the empirical work in this paper as preliminary or ongoing rather than definitive or final. Given the uniqueness of the Thorndike sample and the less than ideal measures of health, the models that I have formulated and estimated should be treated as examples of the kinds of models that could be fitted with longitudinal samples that contain more refined measures of current and past health and background characteristics. Due to the preliminary nature of my work, 


\section{The Correlation between Health and Schooling 205}

I have not hesitated to suggest alternative explanations of certain findings, to speculate and to be provocative in discussing results, and to propose a partial agenda for future research.

One topic on such an agenda would be a careful study of the process by which schooling influences health and other aspects of consumer behavior. In such a study, one would delineate in detail all channels through which the nonmarket productivity effect of schooling on health operates. A second topic would be an examination of the mortality experience of the NBER-Thorndike sample after 1969. A third topic, not previously mentioned, would be a study that takes full account of my notion that children's health is one aspect of their quality. In this research, one would formulate and estimate a demand curve for children's health. One would also use this demand curve to derive and estimate a demand curve for children's medical care along the same lines that $I$ have used in the past to derive and fit a demand curve for adults' medical care (Grossman 1972b). At a somewhat deeper level, my empirical results suggest that what some persons might call "attitudinal variables," such as self-rated health status and job satisfaction, are amenable to economic analysis. Consequently, practitioners of the "new economics of the household" should not relegate the analysis of these variables to sociologists and psychologists, just as they do not relegate the analysis of fertility and contraception to demographers.

\section{APPENDIX}

The empirical analysis in Sections III and IV in this paper is limited to men who responded to both the 1969 and the 1971 NBER questionnaires, were married in 1969 , and were members of the labor force in that year. In addition to these restrictions, men were excluded from the analysis if there was no information on their current health status, age, height, actual weight, full-time salary, family income, wives' schooling, health status in high school, and school-loss weeks. In cases where there were unknown values of variables other than the ones just listed, the mean value of the relevant variable was substituted.

Table A.1 contains means and standard deviations of all variables that are used in Sections III and IV for the sample of 3,534 men. Table A.2 contains a matrix of simple correlation coefficients. Note that the principal components analysis of the test scores was performed on the entire sample of men who responded to the 1969 questionnaire. Therefore, the five ability variables do not necessarily have zero means. 
206 Demographic Behavior of the Household

TABLE A.1

Means and Standard Deviations, Married Men in NBER-Thorndike Sample a

\begin{tabular}{|c|c|c|}
\hline Variable & Mean & $\begin{array}{l}\text { Standard } \\
\text { Deviation }\end{array}$ \\
\hline $\ln H 69$ & 3.938 & .684 \\
\hline$A$ & 46.733 & 2.196 \\
\hline$S$ & 15.054 & 2.431 \\
\hline$S F A T$ & 9.812 & 3.528 \\
\hline$S M O T$ & 9.977 & 3.464 \\
\hline$V$ & .035 & 1.330 \\
\hline$P$ & .012 & 1.304 \\
\hline$M E C H$ & .019 & 1.301 \\
\hline$N U M$ & .072 & 1.454 \\
\hline$G E N$ & .072 & 1.595 \\
\hline $\ln H H S$ & 1.917 & .258 \\
\hline$S W I F E$ & 13.320 & 2.100 \\
\hline$J S A T$ & 4.415 & .786 \\
\hline$W T D I F$ & 23.102 & 16.641 \\
\hline $\ln W$ & . 1.963 & .498 \\
\hline$O T I N C^{b}$ & 1.508 & 5.896 \\
\hline$E X C E L L^{\mathrm{c}}$ & .595 & \\
\hline $\begin{array}{l}\text { EXP } \\
\text { SOUTH }\end{array}$ & $\begin{array}{r}21.387 \\
.229\end{array}$ & 6.807 \\
\hline$C S 1^{\mathrm{c}}$ & .153 & \\
\hline$C S 2^{\mathrm{c}}$ & .265 & \\
\hline$C S 3^{\mathrm{c}}$ & .195 & \\
\hline$C S 4^{\mathrm{c}}$ & .134 & \\
\hline$C S 5^{\mathrm{c}}$ & .148 & \\
\hline
\end{tabular}

a Sample size is 3,534.

b Thousands of dollars.

c Standard deviations of dummy variables not shown. 


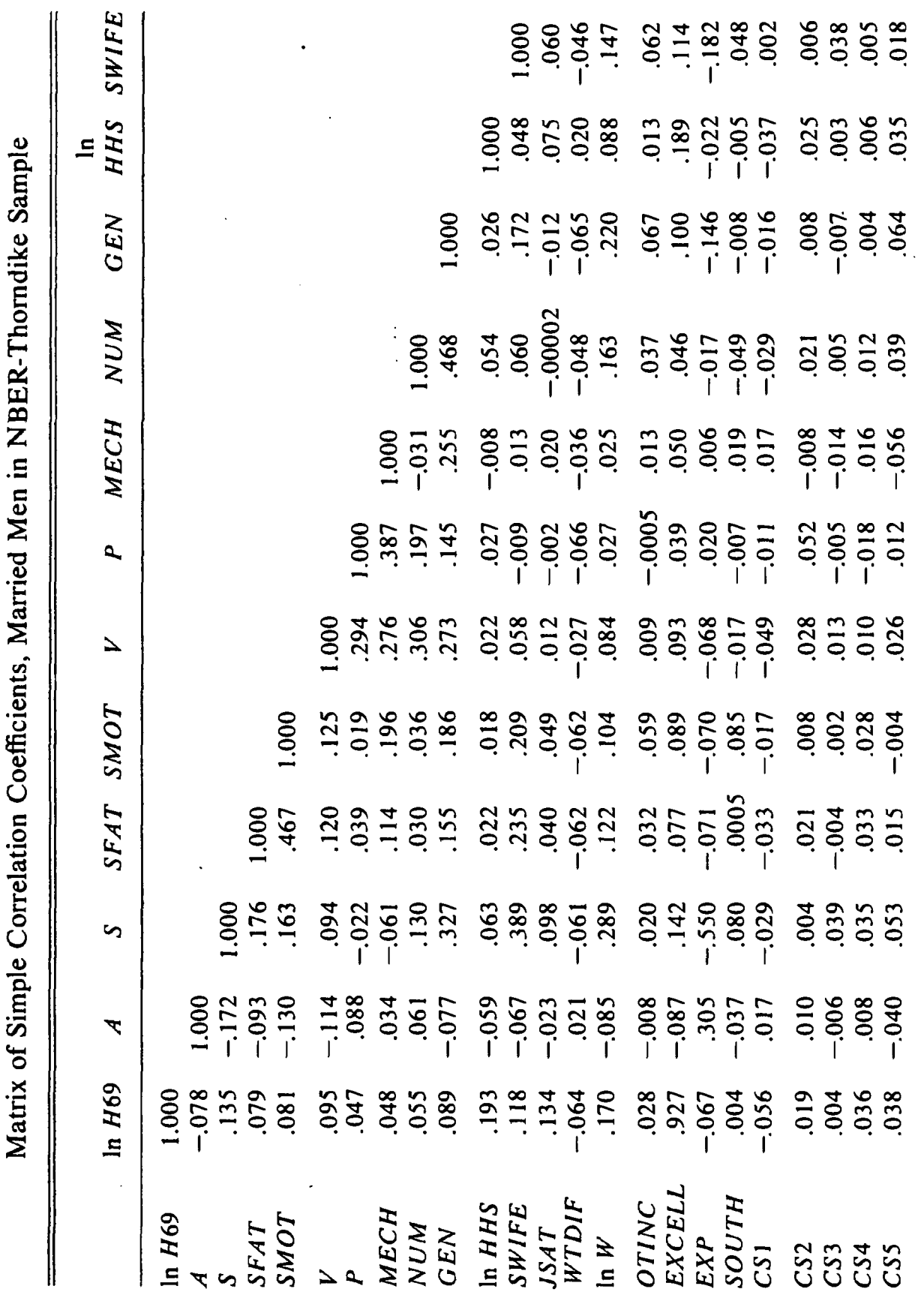




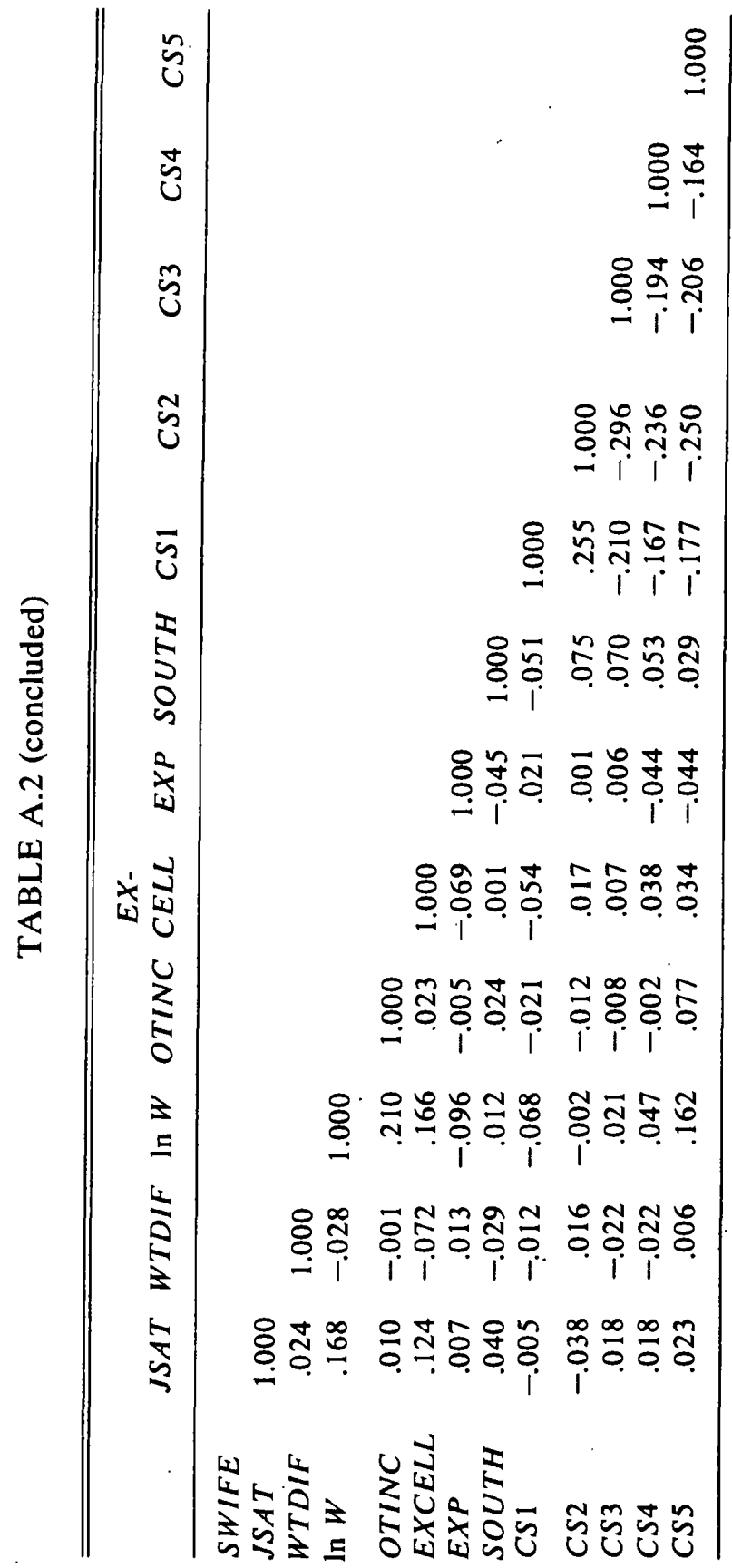




\section{The Correlation between Health and Schooling 209}

\section{REFERENCES}

Andersen, Ronald, and Anderson, Odin W. A Decade of Health Services: Social Survey Trends in Use and Expenditure. Chicago: University of Chicago Press, 1967.

Auster, Richard D.; Leveson, Irving; and Sarachek, Deborah. "The Production of Health: An Exploratory Study." Journal of Human Resources 4 (Fall 1969): 411-436. Reprinted in Victor R. Fuchs, ed., Essays in the Economics of Health and Medical Care. NBER, 1972.

Becker, Gary S. Human Capital and the Personal Distribution of Income: An Analytical Approach. W. S. Woytinsky Lecture No. 1. Ann Arbor: University of Michigan, 1967. . "A Theory of the Allocation of Time." Economic Journal 75 (September 1965): 493-517.

- "A Theory of Marriage: Part I." Joulnat of Political Economy 81 (July/August 1973): 813-846.

Becker, Gary S., and Chiswick, Barry R. "Education and the Distribution of Earnings." American Economic Review, Papers and Proceedings 56 (May 1966): 358-369.

Benham, Lee. "Benefits of Women's Education within Marriage." In T. W. Schultz, ed., Marriage, Family Human Capital, and Fertility. Proceedings of a conference sponsored by the National Bureau of Economic Research and the Population Council. Journal of Political Economy 82, No. 2, Part II (March/April 1974).

. "Resource Allocation and Health Status." In progress.

Ben-Porath, Yoram. "Economic Analysis of Fertility in Israel: Point and Counterpoint." In W. T. Schultz, ed., New Economic Approaches to Fertility. Proceedings of a conference sponsored by the National Bureau of Economic Research and the Population Council. Journal of Political Economy 81, No. 2, Part II (March/April 1973).

- "The Production of Human Capital and the Life Cycle of Earnings." Journal of Political Economy 75 (August 1967): 353-367.

Berkson, Joseph. "Application of the Logistic Function to Bio-Assay." Journal of the American Statistical Association 39 (September 1944): 357-365.

- "Maximum Likelihood and Minimum $\chi^{2}$ Estimates of the Logistic Function." Journal of the American Statistical Association 50 (March 1955): 130-162.

Boskin, Michael J. "The Economics of the Labor Supply." In Glen G. Cain and Harold W. Watts, eds., Income. Maintenance and Labor Supply. New York, Academic Press, 1973.

Bowles, Samuel. "Schooling and Inequality from Generation to Generation." In T. W. Schultz, ed., Investment in Education: The Equity-Efficiency Quandary. Proceedings of a conference sponsored by the Committee on Basic Research in Education of the National Research Council. Journal of Political Economy 80, No. 3, Part II (May/ June 1972).

Breslow, Lester, and Klein, Bonnie. "Health and Race in California." American Journal of Public Health 61 (April 1971): 763-775.

De Tray, Dennis N. "Child Quality and the Demand for Children." In T. W. Schultz, ed., New Economic Approaches to Fertility. Proceedings of a conference sponsored by the National Bureau of Economic Research and the Population Council. Journal of Political Economy 81, No. 2, Part II (March/April 1973).

Fuchs, Victor R. "Some Economic Aspects of Mortality in Developed Countries." In Mark Perlman, ed., The Economics of Health and Medical Care. London: Macmillan, 1974.

- "Some Economic Aspects of Mortality in the United States." New York: National Bureau of Economic Research, 1965. Processed.

Ghez, Gilbert R., and Becker, Gary S. "The Allocation of Time and Goods Over the Life Cycle." New York: National Bureau of Economic Research, 1975.

Greenberg, David H. "Problems of Model Specification and Measurement: The Labor Supply Function." Santa Monica: The RAND Corporation, 1972. Processed. 
Griliches, Zvi, and Mason, William M. "Education, Income, and Ability." In T. W. Schultz, ed., Investment in Education: The Equity-Efficiency Quandary. Proceedings of a conference sponsored by the Committee on Basic Research in Education of the National Research Council. Journal of Political Economy 80, No. 3, Part II (May/ June 1972).

Gronau, Reuben. "The Effect of Children on the Housewife's Value of Time." In T. W. Schultz, ed., New Economic Approaches to Fertility. Proceedings of a conference sponsored by the National Bureau of Economic Research and the Population Council. Journal of Political Economy 81, No. 2, Part II (March/April 1973).

Grossman, Michael. "On the Concept of Health Capital and the Demand for Health." Journal of Political Economy 80 (March/April 1972a): 223-255.

.The Demand for Health: $A$ Theoretical and Empirical Investigation. New York: NBER, $1972 b$.

- "The Economics of Joint Production in the Household." Center for Mathematical Studies in Business and Economics, University of Chicago, 1971. Processed.

Grossman, Michael, and Benham, Lee. "Health, Hours, and Wages." In Mark Perlman, ed., The Economics of Health and Medical Care. London: Macmillan, 1974.

Hall, Robert E. "Wages, Income, and Hours of Work in the U.S. Labor Force." In Glen G. Cain and Harold W. Watts, eds., Income Maintenance and Labor Supply. New York: Academic Press, 1973.

Heckman, James J. "Estimating Indifference Curves to Determine the Effect of Child Care Programs on Women's Work Effort." In T. W. Schultz, ed., Marriage, Family Human Capital, and Fertility. Proceedings of a conference sponsored by the National Bureau of Economic Research and the Population Council. Journal of Political Economy 82, No. 2, Part II (March/April 1974).

. "Shadow Prices, Market Wages, and Labor Supply." Econometrica 42 (July 1974): 679-694.

Hinkle, Lawrence E., Jr., et al. “Occupation, Education, and Coronary Heart Disease." Science 161 (July 19, 1968): 238-246.

Holmes, Thomas H., and Masuda, Minoru. "Life Change and Illness Susceptibility." Paper presented at a symposium on "Separation and Depression: Clinical and Research Aspects." American Association for the Advancement of Science, December 1970.

Johnston, J. Econometric Methods. New York: McGraw-Hill, 1963.

Kitagawa, Evelyn M., and Hauser, Philip M. "Education Differences in Mortality by Cause of Death: United States, 1960." Demography 5, no. 1 (1968): 318-353.

Lancaster, Kelvin J. "A New Approach to Consumer Theory." Journal of Political Economy 75 (April 1966): 132-157.

Leibowitz, Arleen S. "Home Investments in Children." In T. W. Schultz, ed., Marriage, Family Human Capital, and Fertility. Proceedings of a conference sponsored by the National Bureau of Economic Research and the Population Council. Journal of Political Economy 82, No. 2, Part II (March/April 1974).

- "Women's Allocation of Time to Market and Nonmarket Activities: Differences by Education." Ph.D. dissertation, Columbia University, 1972.

Lillard, Lee A. "Human Capital Life Cycle of Earnings Models: A Specific Solution and Estimation." New York: National Bureau of Economic Research Working Paper No. 4, July 1973.

Luft, Harold S. "Poverty and Health: An Empirical Investigation of the Economic Interactions." Ph.D. dissertation, Harvard University, 1972.

Malkiel, Burton G.,. and Malkiel, Judith A. "Male-Female Pay Differentials in Professional Employment." American Economic Review 63 (September 1973): 693-70.5.

Masland, Richard $L$. Tables presented at Twelfth International Congress of Pediatrics, Mexico City, December 1968. 


\section{The Correlation between Health and Schooling 211}

Michael, Robert T. The Effect of Education on Efficiency in Consumption. New York: NBER, 1972.

Michael, Robert T., and Becker, Gary S. "On the New Theory of Consumer Behavior." Swedish Journal of Economics 4 (1973): 378-396.

Mincer, Jacob. "The Distribution of Labor Incomes: A Survey with Special Reference to the Human Capital Approach." Journal of Economic Literature 8 (March 1970): $1-26$.

- Schooling, Experience and Earnings. New York: NBER, 1974.

Muth, Richard. "Household Production and Consumer Demand Functions." Econometrica 34 (July 1966): 699-708.

Nerlove, Marc, and Press, S. James. "Notes on the Log-Linear or Logistic Model for the Analysis of Qualitative Socioeconomic Data." Santa Monica: The RAND Corporation, 1973. Processed.

Netzer, Corinne T. The Brand-Name Calorie Counter. New York: Dell, 1969.

Palmore, Erdman B. "Physical, Mental, and Social-Faciors in Predicting Longevity." The Gerontologist 9 (Summer 1969a): 103-108.

. "Predicting Longevity: A Follow-up Controlling for Age." The Gerontologist 9 (Winter 1969b): 247-250.

Rahe, Richard H. "Subjects' Recent Life Changes and Their Near-Future Illness Reports." Annals of Clinical Research 4 (1972): 250-265.

Rahe, Richard H., and Holmes, Thomas H. "Social, Psychologic, and Psychophysiologic Aspects of Inguinal Hernia." Journal of Psychosomatic Research 8 (1965): 487-491.

Silver, Morris. "An Econometric Analysis of Spatial Variations in Mortality by Race and Sex." In Victor R. Fuchs, ed., Essays in the Economics of Health and Medical Care. New York: NBER, 1972.

Smith, James P. "Family Decisionmaking over the Life Cycle: Some Implications for Estimating Labor Supply." Santa Monica: The RAND Corporation, 1973. Processed:

Stockwell, Edward G. "A Critical. Examination of the Relationship Between Socioeconomic Status and Mortality." American Journal of Public Health 5.3 (June 1963): 956-964.

Taubman, Paul J., and Wales, Terence J. "Higher Education and Earnings: College as an Investment and a Screening Device." New York and Berkeley: National Bureau of Economic Research and Carnegie Commission of Higher Education, 1974.

Thorndike, Robert L., and Hagen, Elizabeth. Ten Thousand Careers. New York: John Wiley and Sons, 1959.

U.S., Department of Health, Education, and Welfare, Public Health Service, National Center for Health Statistics. Vital Statistics of the United States. Volume II: Mortality, Part A, 1961.

Welch, Finis. "Comment: Benefits of Women's Education within Marriage, by Lee Benham." In T. W. Schultz, ed., Marriage, Family Human Capital, and Fertility. Proceedings of a conference sponsored by the National Bureau of Economic Research and the Population Council. Journal of Political Economy 82, No. 2, Part II (March/April 1974).

- "Education in Production:" Journal of Political Economy 78 (January/February 1970): 35-59.

Willis, Robert, "A New Approach to the Economic Theory of Fertility Behavior." In T. W. Schultz, ed., New Economic Approaches to Fertility. Proceedings of a conference sponsored by the National Bureau of Economic Research and the Population Council. Journal of. Political Economy 81, No: 2, Part II (March/April 1973). 


\title{
Comments on \\ "The Correlation between \\ Health and Schooling"
}

\author{
DAN USHER \\ QUEEN'S UNIVERSITY, ONTARIO
}

MICHAEL GROSSMAN'S paper is an extension of the analysis in his pioneering book The Demand for Health. In that work, he develops an inter-temporal model to explain how a person decides on the amount of medical care to purchase today and in every year until the end of his life. The new element in this paper is a critical examination of a twofold interaction between eduçation and health, in which human capital augments the productivity of medical care, and good health augments the rate of return to education.

My comments pertain to the model which is common to this paper and to the book. The model represents what is to the best of my knowledge the first attempt at a complete inter-temporal analysis of the consumer's decision to purchase medical care; and even if, as I think is the case, it is inadequate in certain respects, it is at a minimum a starting point from which economic analysis can proceed. I shall try to assess the reasonableness of some of the assumptions in Grossman's model, to draw out certain unintended implications of the model, and to consider whether the model constitutes an adequate foundation for Grossman's empirical work.

I think it worthwhile to commence by presenting Grossman's model in its entirety. It is set out formally in Table 1 . The model is fairly large and difficult to manipulate, but it seems to be internally consistent, and one can see how the parts fit together. The terminology in the table is exactly Grossman's, except that I have used superscripts to refer to years, subscripts to refer to commodities, and the symbol ^ to designate a vector. 


\section{TABLE 1}

\section{Grossman's Model of Health as it appears in} The Demand for Health ${ }^{\text {a }}$

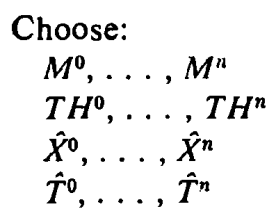

medical expenditure each year $t, i=0 \ldots, n$; time devoted to health care each year $t$; vector of goods consumed each year $t$; and vector of amounts of time devoted to consumption of each good in each year $t$ to maximize $U\left(h^{0}, \ldots, h^{n}\right.$; $\hat{Z}^{0}, \ldots, \hat{Z}^{n}$, where $h^{t}$ is the number of illness-free days in the year $t$ and where $\hat{Z}^{t}$ is a vector of activities in the year $t$.

The constraints are as follows:

i) $H^{t+1}=H^{t}+I^{t}-\delta^{t} H^{t} \quad$ (health accounting identity), where $H$ is one's stock of health from which illness-free days flow, and $I$ is investment in health, and $\delta^{t}$ is the rate of depreciation of health capital in the year $t$.

ii) $H^{0}=\bar{H} \quad$ (endowment of health today).

iii) $I^{t}= \begin{cases}f\left(M^{t}, T H^{t} ; E^{t}\right) & \text { (production function of investment in } \\ 0 \text { if } H^{t}<\overline{\bar{H}} & \text { health in the year } t),\end{cases}$ where $E$ is one's stock of human capital, and $\overline{\bar{H}}$ is the minimum stock of health required to be alive.

iv) $Z_{j}=g_{j}\left(X_{j}, T_{j} ; E_{j}\right) \quad$ (production function of activity $j$ ), where $T_{j}$ is time spent in consuming the good $X_{j}$.

v)

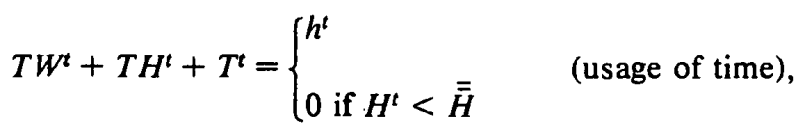

where $T W^{t}$ is time spent working in the year $t$.

vi) $T^{t}=\Sigma_{j} T_{j}^{t}$

vii) $h^{t}= \begin{cases}h\left(H^{t}\right) & \text { (production of illness-free days by means of } \\ 0 \text { if } H^{t} \leqslant \overline{\bar{H}} & \text { health). }\end{cases}$ viii) $\sum_{i j} \frac{X_{j}^{t} P_{j}^{t}}{(1+r)^{t}}=\sum_{i} \frac{W^{t} T W^{t}}{(1+r)^{t}}-\sum_{i} \frac{M^{t} P^{t}}{(1+r)^{t}}$

where $W$ is the wage, $P_{j}$ is the price of the good $j, P^{t}$ is the price of medical care in the year $t$, and $r$ is the externally given rate of interest.

a Michael Grossman, The Demand for Health: A Theoretical and Empirical Investigation (New York: NBER, 1972). 
In the model, utility is a function of activities $\hat{Z}^{t}$ and illness-free days $h^{t}$ in every year of one's life from today, the year 0 , until the year $n$, which is far enough ahead so that no one can expect to live that long. If the consumer dies in the year $t^{*}$, then $\hat{Z}^{t}=0$ and $h^{t}=0$ for every $t \geqslant t^{*}$. The consumer's quota of illness-free days in the year $t$ depends upon his state of health $H^{t}$, which is a variable with the dimension of a stock. Each year the consumer chooses an investment in health $I^{t}$. The rate of depreciation of health capital increases as a man grows older $\left(\delta^{t}>\delta^{t-1}\right)$, and he chooses a length of life such that utility over his lifetime is maximized. The rest of the model shows the allocation of the available time each year among competing uses (equation v), ${ }^{1}$ the identity between the present value of earnings and the present value of expenditures (equation viii), the household production functions of activities with goods and time in the manner of Lancaster (equation vi), and the household production function of investment in health with medicine and time (equation iv).

The first issue I should like to raise may be put in the form of a question: "Why, according to Grossman's model, do I go to the doctor?" The answer is not what one would expect. I do not go to the doctor because I am sick today. I do not go to the doctor because I have a broken arm that must be healed or a flu that must be treated or an appendix that must be removed if $\mathrm{I}$ am to live normally from now on. I go to the doctor to invest in health. Medical expenditure buys an increment to health capital which yields a flow of illness-free days each year for the rest of my life. Except for the effect of depreciation of health capital, there is no special connection between medical expenditure today and illness-free days today, for health capital yields its flow of services steadily over time. If the model were strictly true, we would expect to find a negative correlation among people between current medical expenditure related to heart disease and the incidence of heart disease tomorrow, or between current medical expenditure related to cancer and the incidence of cancer tomorrow. I hope this is not the basis for Grossman's remark on page 152 that researchers have reached "the tentative conclusion that medical care has, at best, a minor impact on health." The model may well be a reasonable representation of the effects of public expenditure on epidemiology.

There is, of course, a sense in which any medical expenditure is an investment in health, for the effects of an untreated illness will linger

\footnotetext{
${ }^{1}$ Equations designated by arabic numerals are from Grossman's paper. Equations designated by roman numerals are from Table 1 above. Equations designated by letters are introduced in this comment.
} 


\section{The Correlation between Health and Schooling 215}

over time. Nonetheless, medical expenditure differs from ordinary investment in two important respects. First, most medical expenditure is not a profitable investment unless I happen to be ill. I cannot obtain a positive rate of return from having a cast put on my arm unless my arm is broken; I cannot obtain a positive rate of return from radiation treatment unless I have cancer. In Grossman's model, one can purchase health capital at any time at all. Second, there is something special about the timing of the benefits of medical expenditure. Some medical expenditure, such as having a case of flu treated, yields me illness-free days in the current year only. Other medical expenditure, such as having an appendix out, is necessary for the preservation of my life. It is not true that all benefits from medical expenditure flow uniformly over time as postulated in Grossman's model.

An alternative way of modeling the decision to purchase medical care is to suppose that health is a disposition not to be sick too often, that falling ill is a random process dependent on the state of one's health, and that medical expenditure can be either a cost of being sick today or an investment in health tomorrow. According to the alternative model, a positive correlation between medical expenditure today and illness tomorrow need not signify that medical expenditure causes illness because today's illness and tomorrow's illness may both be manifestations of a propensity to fall ill and because the benefit of medical expenditure consists in limiting the extent of the discomfort and damage to one's future health when one falls ill.

A second comment may also be introduced by a question, namely, "In what units is health to be measured?" In the model, health is nothing other than the propensity to enjoy illness-free days, for health, $H^{t}$ and illness-free days $h^{t}$ are linked in a one-to-one relation which appears in general form in Table 1 above as equation viii and in constant elasticity form in the paper under review as equation 2

$$
h^{t}=8,760-B\left(H^{t}\right)^{-c}
$$

This equation is something of an exception among postulated stockflow relations because it is nonlinear. It is the practice in accounting and in economics to postulate that stocks and flows are directly proportional. So, for instance, we say that ten workers do ten times the work of one worker, and eight cars yield eight times the service of one car, and $n$ houses yield $n$ units of service, not $n^{2}$ or $\sqrt{n}$ or $h(n)$ where $h$ is an arbitrary function. We measure the size of the stock according to the size of the flow of services it yields, for there is normally no way of distinguishing the size of the stock and the size of the flow indepen- 
dently. To adopt this practice, one would measure the stock of health on a scale from 0 to 365 , and the proper form of equation 2 would be

$$
h^{t}=H^{t}
$$

The issue is confused by the fact that there is a distinction in common speech between health and illness-free days. I may say without contradiction that I was sick for the greater part of last year, but that I do not expect to be sick much from now on, because I am a basically healthy person. However, the distinction in common speech between health and illness-free days is not really a way out of the difficulty, because the source of that difference - the fact that health is a propensity to illness-free days, and that one may be healthy but nonetheless sick, or unhealthy but well, for most of the year -is explicitly assumed away by equation 2 in Grossman's model.

Grossman does try to obtain an independent measure of the stock of health. He makes use of sample surveys in which people are asked, in effect, to specify whether they are (a) very healthy; (b) moderately healthy; (c) moderately unhealthy; or (d) very unhealthy - and $H$ is given values proportional to the average rate of illness of people identifying themselves in each category. There are two main problems with this procedure. The first is that the questionnaire scales health ordinally, so that health can be measured equally well by any four monotonically decreasing numbers. One could have used the numbers $4,3,2,1$ or $4000,300,20,1$ or any decreasing set, and Grossman's way of getting four decreasing numbers seems no better than any other. This matters, because the parameter $c$ in equation 2 could take on any positive value, depending on which set of numbers is chosen. Second, a man who is asked to state how healthy he is can respond by telling us something other than the number of illness-free days he has enjoyed in the last year, because he has a concept of health which is different from that employed in Grossman's model, and not because he makes some mental transformation between $H^{t}$ and $h^{t}$ as implied in equation 2. To postulate that the flow of illness-free days is a curved function of the stock of health, where the stock of health is alleged to be a medical or biological variable, is to put into one's model a term $H$, which is unmeasurable, and to render ambiguous every function in which the term appears.

One might try to avoid these problems by measuring health in financial rather than medical terms. Just as real capital in the automotive industry may be measured as the accumulated and discounted value of investment, so health capital may be measured as accumulated and 
discounted medical expenditure. Indeed, a measure of this kind is implied in the model. Look at equations 1 and 8 together, ${ }^{2}$ and make the special assumption that $\alpha=1$, so that the marginal cost of investment in health is constant. It follows from these equations that health is to be measured in dollars worth, and equation 2 becomes a relation between dollars worth of accumulated investment in health and the number of illness-free days per year.

The difficulty with measuring health in financial terms is that the model acquires an implication that most of us would find unacceptable. Since the cost of health is constant by definition, and since the number of illness-free days is an invariant function of the stock of health, equations 1 and 8 together imply that a man can obtain full health at any age if he is prepared to make the appropriate medical expenditure, that health should be highly correlated with income and wealth as long as longevity is of value in itself, and that if a man is wealthy enough, he can arrange matters so that he lives forever. The observed negative correlation in Grossman's Table 5 between unearned income and health is not implied by the model, except under the special assumption that longevity itself is of no value.

Finally, I should like to make a technical point concerning the derivation of the demand curve for health. Though there is a fairly elaborate model of health set out in Table 1, Grossman makes very little use of it in determining the consumer's behavior. Instead, he employs a relation which is true of any investment whatsoever, as long as the investor makes himself better off by raising the present value of his income stream, and either the capital good can be sold at the end of the current period, or some of the capital good will be bought next year, too. It is an equilibrium condition for such an investment that

$$
M . V . P .=M . C .\left[r+\delta-\frac{1}{M . C .} \frac{d}{d t}(M . C .)\right]
$$

where M.V.P. is marginal value product in the current year; $M . C$. is marginal cost of the capital good; $r$ is the current rate of interest; and $\delta$ is the current rate of depreciation.

All of the terms in equation $B$ can be translated into the language of Grossman's model. From equations 2 and 3, we see that

$$
\text { M.V.P. }=W^{t} G^{t}=W^{t} B C\left(H^{t}\right)^{-c-1}
$$

because it is assumed in the investment version of the model that the

${ }^{2}$ Equations 1 and 8 appear in a slightly altered form as equations $i$ and iii in Table 1. 
value of a marginal illness-free day $G^{t}$ is given by the wage rate $W^{t}$. From equation 8 , it follows that the marginal cost of a unit of health capital is invariant so that

$$
\text { M.C. } \equiv P
$$

From $\mathrm{B}, \mathrm{C}$, and $\mathrm{D}$ one can immediately derive that

$$
\ln H^{t}=\epsilon \ln B C+\epsilon \ln W^{t}-\epsilon \ln P^{t}-\epsilon \ln \left(r^{t}+\delta^{t}-\frac{\dot{P} t}{P^{t}}\right)
$$

which is essentially Grossman's demand for health schedule of equation 9 , where $1 /(1+c)$ is replaced by the variable $\epsilon$.

The demand for health schedule in equation 9 is illustrated in Figure 1. The figure shows the negative relation between $H$ and $r+\delta$ when $W, \delta$, and $P$ are held constant.

The derivation of the demand schedule in equation 9 and Figure 1 is satisfactory as far as it goes, but it is essential to assume that the marginal cost of health capital is constant if $H$ is to be expressed as a unique function of $W, P, r, \dot{P}$ and $\delta$ in the current year. A more likely possibility is that the marginal cost of a given increment to health is an increasing function of investment in health in the current year as represented by the schedule in Figure 2. In that case, the market price $P$ in equation $\mathrm{E}$ would have to be replaced by M.C., which is a function of the flow of health in the current year and the term $\frac{1}{P} \frac{d}{d t}(P)$ would have to be replaced by the term $\frac{1}{M . C .} \frac{d}{d t}(M . C$.$) , which is de-$ pendent on the rates of depreciation of health in every future year until the end of a man's life. We are confronted with Hobson's choice. Either

\section{FIGURE 1}

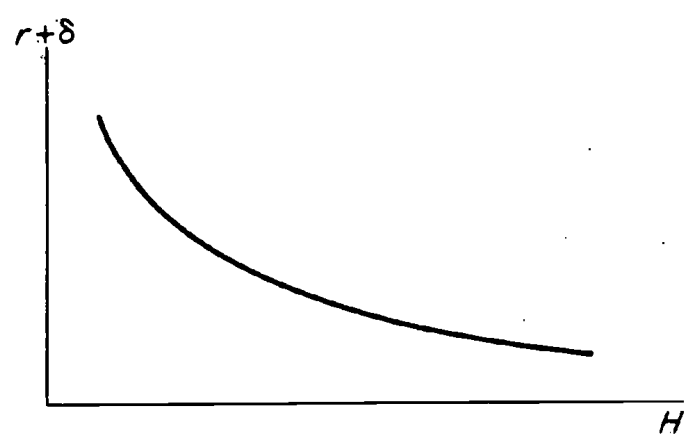




\section{The Correlation between Health and Schooling 219}

FIGURE 2

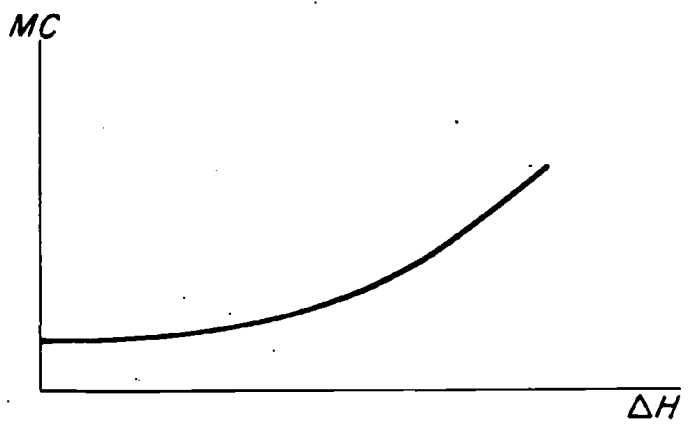

we assume that $P^{t}$ is independent of the amount of investment in health, in which case, as mentioned above, a wealthy enough man can choose to live forever, or we restrict the options for investing in health by postulating a schedule such as is shown in Figure 1, in which case the optimal quantity of health today depends on all the parameters in the model, all wages, all depreciation rates, and all prices of health capital from now until the end of one's life.

Consider Grossman's full model once again. Although the mathematics required to derive time series of endogenous variables such as $\hat{Z}^{t}, h^{t}, H^{t}$ is very complex, it seems reasonable to assume that some solution exists, and, in particular, that $H^{t}$ has some determinate history from time 0 to time $t^{*}$, when our consumer chooses to die. One such history, in which health declines from $\bar{H}$ at time 0 to $\overline{\bar{H}}$ at time $t^{*}$, is illustrated in Figure 3. Furthermore, though I cannot work it out explicitly, there must be some comparative dynamic solution to

FIGURE 3

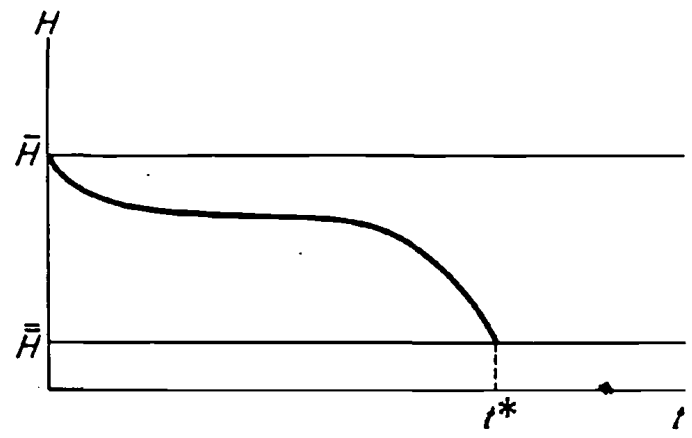


the problem in which $H^{t}$ in any year $t$ is a function of all of the exogenous variables

$$
H^{t}=H^{t}\left(\hat{r}, \hat{W}, P, \hat{\delta}, E ; f, \hat{g}_{j}, h\right),
$$

where $\hat{r} ; \hat{W}$, and $\hat{\delta}$ are vectors of the rate of interest, the wage rate, and the rate of depreciation of health capital in all future years; where $P$ and $E$ represent all prices and environmental conditions; and where $f, \hat{g}_{j}$, and $h$ are the functional forms of the constraints. It seems reasonable to suppose that the partial derivative of $H^{t}$ with respect to $r^{t}$ is negative, though Grossman does not prove it, and I cannot.

In the final analysis, my dissatisfaction with Grossman's derivation of the demand curve for capital lies in the fact that he uses the methods of comparative statics in circumstances in which comparative dynamics would seem to be appropriate. ${ }^{3}$ The demand curve for capital in which the desired stock depends on its price or on the rate of interest, independently of time or history, is a construct that is valid only in a world where there is no history. It does not exist in a world where life is finite and the benefits that flow from a given stock of health capital depend on the rates of depreciation throughout one's life.

On the empirical work, I would like to make three points: First, nothing in the model suggests that education ought to lead to good health. The proposition is not inconsistent with the model, and it can be made very plausible on other grounds, but it is not implied. Second, the model does suggest that there should be a strong positive correlation between income and health because health can be purchased at constant marginal cost. Third, I suspect that much, if not all, of the empirical work can stand regardless of the model.

\footnotetext{
${ }^{3}$ Some investigation of the subject of comparative dynamics has been undertaken by my colleague Hajimi Oniki. Perhaps the methods employed in the Heckman and Willis paper in this volume can be of use.
} 


\section{Reply to Dan Usher}

\section{MICHAEL GROSSMAN}

IN general, Usher ignores most of the work that I have done in this paper. Instead, he criticizes my theoretical model of the demand for health and medical care (Grossman 1972a, 1972b) that I use as a point of departure for my present paper. In what follows, I reply to his major points.

Usher claims that my model cannot account for an observed negative relationship between medical care and health. That is, it cannot explain why sicker people are likely to report higher outlays on medical care than healthy people. I do not agree. An increase in the rate of depreciation on health capital would raise the shadow price of health and would cause the quantity of health capital demanded to fall. At the same time, the quantity of medical care demanded would rise, provided the price elasticity of demand for health were smaller than one. With the depreciation rate held constant, health and medical care should be positively related. But since it is not possible to control completely for these variations empirically, the gross correlation is negative. (For a detailed discussion, see Grossman 1972b, pp. 43-44 and p. 48.)

My statement that researchers have reached the tentative conclusion that medical care has, at best, a minor marginal impact on health is based on sophisticated studies that take account of the two-way relationship between these variables. These studies estimate the effect of medical care on health either by using two-stage least squares or by employing proxy measures of preventive medical care. This conclusion is not, as Usher implies, based on ordinary least squares regressions of health on medical care outlays.

I agree with Usher that my model does not explicitly deal with uncertainty (random illness). Indeed, I, myself, have pointed out that the model should be extended along these lines by assuming that a given consumer faces a probability distribution of depreciation rates at any age (Grossman 1972a, pp. 247-248). Using my basic framework, Phelps (1973) has shown that the introduction of uncertainty does not alter the basic properties of the demand curve for medical 
care that I derive. Moreover, Rand and I (Grossman and Rand 1974) have demonstrated that my model can be used as the basis for constructing separate demand curves for preventive and remedial medical care.

Usher criticizes my assumption that the relationship between the stock of health and the flow of healthy days is nonlinear. I make this assumption because the output produced by health capital has a finite upper limit of 365 healthy days in a year. Therefore, I assume that the marginal product of health capital diminishes. This, together with the assumption that the marginal cost of investment in health is constant, means that the demand curve for health capital depends only on current values of the exogenous variables.

I agree with Usher that, given constant cost and constant marginal product, the optimal stock of health would essentially be infinite. I also agree that, given rising marginal cost, the demand curve would depend on future values. Nonetheless, I see no reason to complicate what is an already complicated model by introducing rising marginal cost. The basic nature of health capital suggests that its marginal product should fall. I admit that if one took account of the quality of the output of health capital as well as the quantity, diminishing marginal productivity would be somewhat less plausible. Since, however, the stock of health is specific to an individual and is used in the household as well as in the market, the marginal product of this capital should diminish after some point.

The assumption of linear stock-flow relationships is not as universal as Usher would have us believe. Rosen (1969) assumes that labor input depends on employment and hours per man but that this input is not simply the product of employment and hours per man. Jorgenson (1967), Arrow (1968), and Sandmo (1971) construct models of the demand for capital stock by firms in which the marginal cost of gross investment is constant. In these models, capital services are proportional to capital stock. The firm's production function, however, exhibits diminishing returns to scale in all inputs, so that output and demand for inputs are finite. Provided gross investment is positive, these models generate myopic demand curves for physical capital that are very similar to my demand curve for health capital.

Usher claims that if healthy time is a curved function of the stock of health, then the latter variable cannot be measured, and all functions containing it become ambiguous. As I imply in Section II.B of my paper, given the functional form specified in equation 12 , my health 


\section{The Correlation between Health and Schooling}

capital series is unique up to a linear transformation. That is, it is essentially cardinal in nature, rather than ordinal. In my discussion of this series, $I$ also indicate that it does not change very much when a more complicated functional form is selected.

I agree with Usher that the parameter $C$ in equation 12 could take on any value. But in the context of regression analysis, tests of significance are not affected by the value of $C$. In the few instances in which I discuss quantitative rather than qualitative effects, I do assume that $C$ is equal to one. One rationale for this assumption is that it generates a reasonable value for the price elasticity of demand for medical care. Suppose, for example, that substitution between medical care and own time in the production of health were difficult, and that medical care accounted for one-half of the total cost of producing health. Then if $C$ were equal to one, the price elasticity of medical care would approximately equal one-quarter. This figure is within the range of existing estimates. (See, for example, Phelps and Newhouse 1973.)

\section{REFERENCES}

Arrow, Kenneth J. "Optimal Capital Policy with Irreversible Investment." In J. N. Wolfe, ed., Value, Capital and Growth. Edinburgh: Edinburgh University Press, 1968. Grossman, Michael. "On the Concept of Health Capital and the Demand for Health." Journal of Political Economy 80 (March/April 1972a): 223-255.

. The Demand for Health: $A$ Theoretical and Empirical Investigation. New York: NBER, $1972 b$.

Grossman, Michael, and Rand, Elizabeth H. "Consumer Incentives for Health Services in Chronic Illness." In Selma J. Mushkin, ed., Consumer Incentives for Health Care. New York: Prodist for the Milbank Memorial Fund, 1974.

Jorgenson, Dale W. "The Theory of Investment Behavior." In Robert Ferber, ed., Determinants of Investment Behavior. New York: NBER, 1967.

Phelps, Charles E. "Demand for Health Insurance: A Theoretical and Empirical Investigation." Santa Monica: The RAND Corporation, 1973.

Phelps, Charles E., and Newhouse, Joseph P. "Coinsurance and the Demand for Medical Services." Santa Monica: The RAND Corporation, 1973.

Rosen, Sherwin. "On the Interindustry Wage and Hours Structure." Journal of Political Economy 77 (March/April 1969): 249-273.

Sandmo, Agnar. "Investment and the Rate of Interest." Journal of Political Economy 79 (November/December 1971): 1335-1345. 
